\title{
Survival and Control of Campylobacter in Poultry Production Environment
}

\author{
Mohammed J. Hakeem ${ }^{1,2}$ and Xiaonan $L u^{1,3 *}$ \\ ${ }^{1}$ Food, Nutrition and Health Program, Faculty of Land and Food Systems, The University of British Columbia, Vancouver, \\ BC, Canada, ${ }^{2}$ Department of Food Science and Human Nutrition, College of Food and Agriculture Sciences, King Saud \\ University, Riyadh, Saudi Arabia, ${ }^{3}$ Department of Food Science and Agricultural Chemistry, Faculty of Agricultural and \\ Environmental Sciences, McGill University, Ste Anne de Bellevue, QC, Canada
}

OPEN ACCESS

Edited by:

Shymaa Enany,

Suez Canal University, Egypt

Reviewed by:

Aymen Yassin,

Cairo University, Egypt

Ramy Karam Aziz,

Cairo University, Egypt

Reham Samir,

Cairo University, Egypt,

in collaboration with reviewer RKA

*Correspondence:

Xiaonan Lu

xiaonan./u@mcgill.ca

Specialty section:

This article was submitted to Molecular Bacterial Pathogenesis,

a section of the journal

Frontiers in Cellular

and Infection Microbiology

Received: 08 October 2020

Accepted: 15 December 2020

Published: 29 January 2021

Citation:

Hakeem MJ and LuX (2021) Survival and Control of Campylobacter in Poultry Production Environment. Front. Cell. Infect. Microbiol. 10:615049. doi: 10.3389/fcimb.2020.615049
Campylobacter species are Gram-negative, motile, and non-spore-forming bacteria with a unique helical shape that changes to filamentous or coccoid as an adaptive response to environmental stresses. The relatively small genome (1.6 Mbp) of Campylobacter with unique cellular and molecular physiology is only understood to a limited extent. The overall strict requirement of this fastidious microorganism to be either isolated or cultivated in the laboratory settings make itself to appear as a weak survivor and/or an easy target to be inactivated in the surrounding environment of poultry farms, such as soil, water source, dust, surfaces and air. The survival of this obligate microaerobic bacterium from poultry farms to slaughterhouses and the final poultry products indicates that Campylobacter has several adaptive responses and/or environmental niches throughout the poultry production chain. Many of these adaptive responses remain puzzles. No single control method is yet known to fully address Campylobacter contamination in the poultry industry and new intervention strategies are required. The aim of this review article is to discuss the transmission, survival, and adaptation of Campylobacter species in the poultry production environments. Some approved and novel control methods against Campylobacter species throughout the poultry production chain will also be discussed.

Keywords: Campylobacter, survival, control, poultry-processing plants, poultry farms

\section{INTRODUCTION}

The name of Campylobacter [kam"po-lo-bak'tor] originally came from the ancient Greek meaning curved rod where kampylos means curved and baktron means rod. However, the unique shape of Campylobacter looks more like a spiral or helical one rather than a curved rod shape. Campylobacter can change its shape into filamentous or coccoid to adapt to the stressful conditions (Gaynor et al., 2005; Tresse et al., 2017). It was first isolated from a sheep abortion case and classified as a Vibriolike bacterium (McFadyean and Stockman, 1913; Skirrow, 2006) and then renamed as Campylobacter after showing a clear different taxonomy profile from the Vibrio species. Campylobacter bacteria are very diverse microorganisms not only on the species levels but also on the subspecies and strain levels (Gaynor et al., 2005; Vidal et al., 2016). Diversity includes differences in genetic and phenotypic characteristics as well as growth requirement, which may 
explain their presence in different hosts or ecological niches including different poultry and wild birds. Some Campylobacter species are flagellated with a single polar flagellum or bipolar flagella (e.g., C. jejuni, C. coli C. concisus and C. showae), while fewer species (e.g., C. hominis and C. ureolyticus) have no flagellum (Man, 2011).

Emerging Campylobacter bacteria are species that have been identified recently to cause illnesses (Kaakoush et al., 2015). They include C. concisus, C. curvus, C. fetus, C. gracilis, C. mucosalis, C. pinnipediorum, C. rectus, C. showae, C. sputorum, C. lari, C. ureolyticus, C. upsaliensis, and C. volucris. The clinical importance and pathogenicity of emerging Campylobacter species have been reviewed (Man, 2011; Costa and Iraola, 2019). Available evidence showed that they could attach and invade human epithelial cells, alter intestinal barrier integrity, avoid host immune response, secrete toxins and invade macrophages. In contrast, the actual contribution of emerging Campylobacter species to campylobacteriosis is still not clear because available cultivation methods including hydrogenenhanced microaerobic and anaerobic conditions failed to successfully grow these microbes under the laboratory condition (Kaakoush et al., 2015). This is due to several reasons including the slow growing nature of some fastidious species or individual strains, growth inhibition by antibiotics added in selective media, limited hydrogen source, presence of competitive microorganisms, and/or difficulties in identifying some Campylobacter species due to their morphological diversities. Nevertheless, hydrogen enhancement (generally 3$7 \%)$ in the microaerobic condition improved the detection of C. concisus from $0.03 \%$ to $1.92 \%$ (Casanova et al., 2015). Symptoms of C. concisus infections and other Campylobacter bacterial infections are usually milder than that with C. jejuni and C. coli. However, emerging Campylobacter species are also important and require better isolation techniques for their detection and diagnosis. A previous report showed that infections of C. concisus and C. fetus were more common than infections of C. jejuni and C. coli in the elderly (68.4 years old) than young adults of 28.6 years old on average (Bessède et al., 2014). In conclusion, although C. jejuni and C. coli remain the leading cause of campylobacteriosis, more effective detection methods are required for a better understanding of how emerging Campylobacter bacteria evolve in the environment, transmit to agri-food systems, and contribute to campylobacteriosis.

Available evidence suggests that campylobacteriosis incidence has been rising in both developed and developing countries in the recent years (Kaakoush et al., 2015). The size of Campylobacter outbreaks in different countries ranged from 10 to 100 cases between 2007 and 2013 (Kaakoush et al., 2015). Poultry and untreated water were the most reported sources of Campylobacter outbreaks. The number of Campylobacter cases in different countries within the same region can vary significantly. This is not only due to the unreported cases but also limited sensitivity of detection methods, population size and composition, variation in public health standards, intervention strategies, surveillance systems, food safety practices, and the prevalence of Campylobacter in natural reservoirs in different regions. The epidemiological data from Asia, Africa, and the Middle East shows that Campylobacter infection is prevalent in this region although the data is incomplete. The total number of Campylobacter infections in Canada was estimated to be about 145,350 cases per year (Thomas et al., 2013). British Columbia (BC) had an annual Campylobacter infection rate of 37.74 cases per 100,000 people ( 1,818 cases) in 2017 (BC Center for Disease Control, 2017). In comparison, Japan had a rate of 1,512 cases per 100,000 people (Kubota et al., 2011) and New Zealand had a rate of 161.5 per 100,000 people (Sears et al., 2011) within the last decade. In USA, the surveillance system, new regulations, and control strategies have contributed to the decline of several foodborne pathogens including Salmonella, Listeria, and E. coli O157:H7 from 2006 to 2014, but not Campylobacter and Vibrio (Crim et al., 2014). Altogether, both individual cases and outbreaks of campylobacteriosis are generally prevalent around the world.

Several risk factors that can lead to Campylobacter infections include traveling or person-to-person transmission, contact with animals, and consumption of contaminated food or water. Metaanalysis data suggest that international and domestic traveling was the most critical risk factor of Campylobacter infections, followed by the consumption of uncooked chicken meat, environmental exposure, and direct contact with the farm animals. A Canadian report showed that campylobacteriosis was responsible for the highest number of causes of travelrelated diseases [123/446 cases (27.57\%)] from 2005 to 2009 (Ravel et al., 2010). In addition, overlapping exists between risk factors. For example, travel-related diseases are frequently linked to the consumption of contaminated foods (Kaakoush et al., 2015). Although traveling abroad contributes to the overall Campylobacter transmission, the spread of antibiotic-resistant Campylobacter strains between countries and continents through international agri-food trade is also a considerable public health concern (Mughini-Gras et al., 2014).

\section{THE UNIQUE PHYSIOLOGY OF CAMPYLOBACTER}

Campylobacter species are not only unique in their shape, but they also have a relatively small genome with unique cellular and molecular physiology compared to other foodborne pathogens. The first whole-genome sequencing analysis of C. jejuni (NCTC11168 strain) showed that the genome (1.6 Mbp) has uniquely a limited number of repeated sequences and no insertion or phage associated regions (Parkhill et al., 2000). Other reports showed that C. jejuni lacks the regulator rpoS (starvation/stationary phase sigma factor) and their stationaryphase cultures are ununiformed dynamic populations unlike most of other bacteria (Kelly et al., 2001). This could be a survival strategy that $C$. jejuni uses to reduce its starvation stress during the stationary phase at least in some strains. Although the existence of stationary phase in C. jejuni is elusive, a transition from exponential to stationary phase was observed in C. jejuni populations with a number of changes in 
the transcriptomic and proteomic profiles between the two phases (Turonova et al., 2017). These data also suggest that the pleiotropic regulator $\cos R$ gene acts as a negative autoregulator and is alternative to rpoS gene in C. jejuni during the stationary phase of growth. In addition, $C$. jejuni is an asaccharolytic bacterium (i.e., unable to break down carbohydrate for energy) due to the absence of some key glycolytic enzymes [e.g., glucokinase (GIK) and phosphofructokinase (Pfk)] that involved in the functional Embden-Meyerhof-Parnas glycolysis pathway (Tresse et al., 2017). Campylobacter is also a chemoorganotrophic bacterium that oxidizes the chemical bonds in amino acids or intermediate molecules of tricarboxylic acid (Krebs) cycle as their energy and carbon source. Moreover, C. jejuni uses gluconeogenesis fueled by amino acids to generate glucose from non-carbohydrate sources. The EntnerDoudoroff (ED) pathway is used in bacteria for synthesizing pyruvate from extracellular glucose. A complete group of genes encoding ED pathway was identified in some rare C. jejuni and C. coli isolates (Vegge et al., 2016). Interestingly, this gene set increased the survival and biofilm formation in Campylobacter. Altogether, C. jejuni lacks many important stress response genes, but has developed different mechanisms to adapt to and survive in the new environmental and/or under stress conditions.

Campylobacter species have many unique growth requirements that can limit but not eliminate their prevalence outside warm-blooded hosts in foods and/or food environments. Most Campylobacter bacteria grow optimally at either $42^{\circ} \mathrm{C}$ (chicken body temperature) or $37^{\circ} \mathrm{C}$ (human body temperature), but none of them can grow below $30^{\circ} \mathrm{C}$ (Park, 1996). The growth rate of most other bacteria reduces gradually near their minimum growth temperature unlike Campylobacter that suddenly stops to grow below $30^{\circ} \mathrm{C}$ (Hazeleger et al., 1998). No growth adaptation of $C$. jejuni was observed below $30^{\circ} \mathrm{C}$. This raises the question of how different the metabolic activity of Campylobacter is below and above the minimum growth temperature. This question will be answered below according to several reports about the survival of Campylobacter in food and food-related conditions. Moreover, Campylobacter is unable to survive under the ambient oxygen level due to several combined reasons (Mace et al., 2015). These include (i) limited tolerance against reactive oxygen species (ROS), (ii) incompetence of producing adequate antioxidant enzymes, (iii) low respiratory rate, and (iv) presence of oxygen-labile essential enzymes (Velayudhan et al., 2004). A few enzymes present in Campylobacter are believed to play a critical role in protecting the cells from oxygen tension. These include catalase, glutathione reductase, glutathione synthetase, peroxidase, and superoxide dismutase (Keener et al., 2004).

\section{HUMAN INFECTIONS}

Campylobacter is documented in 2019 to be the leading foodborne pathogen associated with the consumption of animal-source food products worldwide (Li et al., 2019). Classical symptoms of Campylobacter infections (called campylobacteriosis) include fever, severe watery or bloody diarrhea, cramps, and weight loss for 6 days on average in humans (V'eron and Chatelain, 1973; Kaakoush et al., 2015). Most infections are self-limiting and do not require medical therapy other than hydration and electrolyte balance (Acheson and Allos, 2001). Antibiotic treatment is only applied either in severe cases or to immunocompromised individuals. C. jejuni and $C$. coli are the major causes of campylobacteriosis in humans (Kaakoush et al., 2015). Several studies showed that infections of both $C$. jejuni and $C$. coli occur more frequently during the summer than other seasons (Nielsen et al., 2013; Bessède et al., 2014). C. jejuni infection is greater than C. coli in many countries, but $C$. coli is also an important species and reported to be the second most contributor to campylobacteriosis after C. jejuni. In fact, a comparison study of patients infected with either $C$. jejuni or $C$. coli showed that slightly older patients (34.6 compared to 27.5 years old) have a greater risk of being infected with $C$. coli than C. jejuni (Bessède et al., 2014). Campylobacteriosis has also been linked to a range of gastrointestinal conditions, such as inflammatory bowel diseases (IBD), periodontitis, esophageal disease, functional gastrointestinal disorders, celiac disease, and colon cancer in humans (Véron and Chatelain, 1973; Kaakoush et al., 2015). C. jejuni infections may lead to autoimmune disorders known as Guillain-Barré syndrome (GBS) and Miller Fisher syndrome. According to an infection study of 111 volunteers, C. jejuni dosage correlated with colonization rate, but not with the development of illnesses (Black et al., 1988). The infectious dose to develop campylobacteriosis varied depending on immunity and health status of the individuals. Only 800 Campylobacter cells were able to cause diarrhea to some volunteers, while other data showed that campylobacteriosis was developed with a dose as low as 360 cells (Hara-Kudo and Takatori, 2011). Several genes, proteins and components of C. jejuni are involved in different virulence factors (Table 1).

\section{SURVIVAL IN FOOD AND FOOD-RELATED CONDITIONS}

Campylobacter is sensitive to food and food processing-related stresses. It is more sensitive to heat treatment compared to other foodborne pathogens. For example, the $D$-value of $E$. coli is five times higher than that of C. jejuni at $55^{\circ} \mathrm{C}$ (Rusin et al., 1997). Simply freezing at $-15^{\circ} \mathrm{C}$ could reduce $C$. jejuni count by $3 \log$ CFU/g in ground beef (Stern and Kotula, 1982). Desiccation at room temperature inactivated Campylobacter within a few days (Doyle and Roman, 1982b). Campylobacter cannot survive for a long period of time on food contact surfaces, such as cutting boards, countertops, equipment or kitchen utensils. In contrast, Campylobacter can remain viable on fresh foods, such as ground beef (Stern and Kotula, 1982), fresh produce (Kärenlampi and Hänninen, 2004), fresh chicken (Blankenship and Craven, 1982), and milk (Doyle and Roman, 1982b) during the entire shelf life up to 3 weeks. In addition, the combination of these wet and cold refrigeration conditions of fresh foods assists Campylobacter in 
TABLE 1 | Examples of some important virulence factors and their roles in C. jejuni.

\begin{tabular}{|c|c|c|c|}
\hline Virulence factors & $\begin{array}{l}\text { C. jejuni gene, protein, } \\
\text { or component }\end{array}$ & Role & References \\
\hline \multirow[t]{5}{*}{ Stress response } & CosR & Oxidative stress response regulator & (Hwang et al., 2011) \\
\hline & GroESL & Heat shock operon & (Thies et al., 1999) \\
\hline & DnaJ & Heat shock protein & (Konkel et al., 1998) \\
\hline & Lon protease & Heat shock protein & (Thies et al., 1999) \\
\hline & RacR-RacS & Regulate temperature during growth and colonization & (Brás et al., 1999) \\
\hline \multirow{5}{*}{$\begin{array}{l}\text { Motility and } \\
\text { chemotaxis }\end{array}$} & fliA & Flagellar (sigma 28) $\rightarrow$ regulates the transcription of flagellar genes & (Jagannathan et al., 2001) \\
\hline & ropN & Flagellar (sigma 54) $\rightarrow$ regulates the transcription of flagellar genes & (Jagannathan et al., 2001) \\
\hline & $\mathrm{FlgR}, \mathrm{S}$ & Regulate the flagellum protein biosynthesis & (Hendrixson, 2006) \\
\hline & CheA, B, R, W, V, Y & Chemotaxis signal transduction (Che) proteins network. & (Chandrashekhar et al., 2017) \\
\hline & CheY & Response regulator used for flagellar rotation & (Yao et al., 1997) \\
\hline \multirow[t]{4}{*}{ Adhesion } & RacR-RacS & Persistent colonization of the gut. & (Van der Stel et al., 2015) \\
\hline & LOS & Involved in adherence and display molecular mimicry of neuronal ganglioside $\rightarrow$ & (Young et al., 2007) \\
\hline & CadF & Guillain-Barré syndrome & (Konkel et al., 1997) \\
\hline & & Fibronectin-binding outer membrane protein & \\
\hline \multirow[t]{4}{*}{ Invasion } & Flagellum & Non-flagellated mutants are less invasive. & (Konkel et al., 1999b) \\
\hline & LOS & Lipopolysaccharide $\rightarrow$ Involved in invasion & (Grant et al., 1993) \\
\hline & CPS & Capsular polysaccharide $\rightarrow$ Involved in invasion & (Karlyshev and Wren, 2001) \\
\hline & Cia & Invasive antigens & (Rivera-Amill et al., 2001) \\
\hline \multirow[t]{2}{*}{ Secretion } & pVir & Plasmid found in some C. jejuni isolates led to type IV secretion system. & (Bacon et al., 2002) \\
\hline & $\mathrm{CiaB}$ & Play role in invasion and type III secretion system & $\begin{array}{l}\text { (Konkel et al., 1999a; Konkel } \\
\text { et al., 1999b) }\end{array}$ \\
\hline Toxins & $\begin{array}{l}\text { CdtA, B, C (Cytolethal } \\
\text { distending toxin) }\end{array}$ & Cell distension, cell cycle block and DNA damage $\rightarrow$ Cell death. & (Lara-Tejero and Galán, 2001) \\
\hline
\end{tabular}

surviving on dry surfaces for a few weeks instead of a few days (Doyle and Roman, 1982a; Stern and Kotula, 1982).

Refrigeration is one of the most common food preservation methods either used alone or in combination with other antimicrobial strategies or food preservation methods such as the addition of preservatives, irradiation, or modification of atmosphere. Campylobacter grows in a limited temperature range compared to other food microorganisms (Figure 1). The growth rates of the majority of microorganisms drop to the minimum or stop at refrigeration temperatures. However, fewer pathogenic and spoilage bacteria can grow from a few cells to a large number (e.g., psychrotrophic bacteria) and cause serious food poisonings (Chan and Wiedmann, 2008) or spoilage recall incidents that can be associated with food loss and negative impact on the economy (Pothakos et al., 2014). Pseudomonas species (Chouliara et al., 2007; Zhang et al., 2012; Al-Nehlawi et al., 2013), lactic acid bacteria (Chouliara et al., 2007;
Doulgeraki et al., 2012; Zhang et al., 2012), and Brochothrix thermosphacta (Chouliara et al., 2007; Zhang et al., 2012) are considered as the most problematic spoilage psychrotrophic bacteria in poultry meat. In contrast, Campylobacter and Salmonella are the most causes of human gastroenteritis due to poultry meat consumption (Rouger et al., 2017). Campylobacter in poultry is ranked as the leading pathogen-food combination to cause health risks and negatively impacts the economy (Batz et al., 2012). Kaakoush and others reported that poultry consumption was the most cause of campylobacteriosis outbreaks between 2007 and 2013 (Kaakoush et al., 2015). A more recent report showed that 28 campylobacteriosis outbreaks were linked to the consumption of chicken livers in USA between 2000 and 2016 (Lanier et al., 2018). Up to $90 \%$ of commercially available chicken meat in different regions has been identified to be contaminated by Campylobacter at $\sim \log 4 \mathrm{CFU} /$ carcass (Willis and Murray, 1997; Jorgensen et al., 2002; Walker et al., 2019).

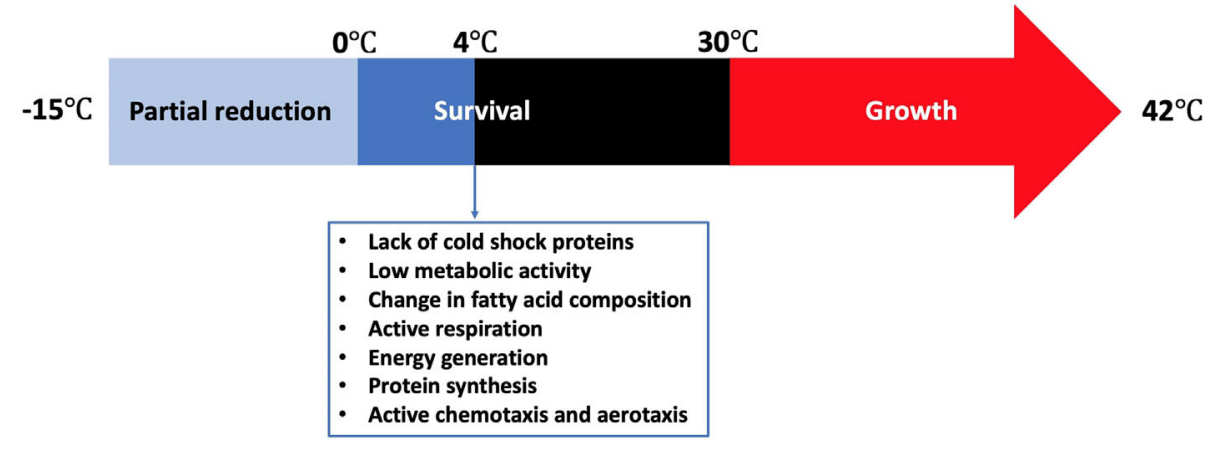

FIGURE 1 | Temperature range for the survival of Campylobacter and its stress response at $4^{\circ} \mathrm{C}$. 
Cold stress response of Campylobacter is significantly different from other common foodborne pathogens. Although Campylobacter lacks cold shock proteins, this microbe can still be active during the shelf life of different refrigerated foods or during the winter season in the agro-ecosystem (Murphy et al., 2006). Hazeleger and others compared the changes in fatty acid composition of the membrane of coccoid-shaped Campylobacter cells with that of the spiral-shaped cells incubated at $4^{\circ} \mathrm{C}$ (Hazeleger et al., 1995). The change in the fatty acid composition in both groups was similar. In contrast, a significant change in the composition of fatty acids occurred when the cells were incubated either at $12^{\circ} \mathrm{C}$ or $25^{\circ} \mathrm{C}$. This included a significant increase in the percentage of 16:0 and 18:0 fatty acids and a significant decline in the percentage of 14:0, 16:1 and 19:0 fatty acids. The same group reported in another study that the vital processes of $C$. jejuni including cellular respiration, catalase activity, energy generation, and protein synthesis were still be functional at $4^{\circ} \mathrm{C}$, which was far below the minimum growth temperature at $30^{\circ} \mathrm{C}$ (Hazeleger et al., 1998). The total amount of ATP (i.e., produced + consumed) as indicated by the respiration rate at $4^{\circ} \mathrm{C}$ was only $5 \%$ of that at $40^{\circ} \mathrm{C}$, suggesting that $C$. jejuni has a relatively low metabolic activity at low temperatures. However, the concentration of the produced ATP at $4^{\circ} \mathrm{C}$ was almost $50 \%$ of that at $40^{\circ} \mathrm{C}$. Physiological functions such as chemotaxis and aerotaxis were similarly observed at 4,20 , and $40^{\circ} \mathrm{C}$, indicating that C. jejuni could normally move toward substrates even below $30^{\circ} \mathrm{C}$. The effect of cold exposure (i.e., $6^{\circ} \mathrm{C}$ for $24 \mathrm{~h}$ ) on the thermal tolerance (i.e., $56^{\circ} \mathrm{C}$ ) of C. jejuni was compared with that of E. coli $\mathrm{K}-12$ (Hughes et al., 2009). C. jejuni was more tolerant than E. coli $\mathrm{K}-12$ to thermal treatment as the ratio of the unsaturated to saturated fatty acids did not change after cold exposure, which was different from that of E. coli K-12. In conclusion, Campylobacter not only remains viable at low temperatures but also maintains sufficient metabolic activity to survive and move to the favorable places even in the absence of cold shock proteins.

\section{CAMPYLOBACTER IN POULTRY FARMS}

\section{Transmission into Poultry Farms}

Poultry has been considered as the major source of food-related transmission of Campylobacter species to humans since the early years of poultry industry (Skirrow, 1977). C. jejuni is a common commensal microorganism in chicken microbiome (Hendrixson and DiRita, 2004; Awad et al., 2016; Ijaz et al., 2018). Poultry is also a reservoir of other Campylobacter species including C. lari, C. upsaliensis, and C. concisus (Kaakoush et al., 2014). This bacterium usually transmits horizontally from different environmental sources to flocks (Sahin et al., 2002; Kaakoush et al., 2015). It was reported that Campylobacter species are usually abundant in the surrounding environment of poultry farms, such as soil, water source, dust, surfaces and air (EllisIversen et al., 2012). Animal feed and/or drinking water can transmit Campylobacter from the environment to poultry farms.
Farmers and farm visitors who carry Campylobacter can also transmit this microbe to poultry farms. Several studies isolated Campylobacter from wild bird feces around poultry houses, suggesting that wild birds contributed to the transmission of this microbe into the poultry houses (Craven et al., 2000; Hiett et al., 2002). For example, a molecular subtype analysis showed that 12 Campylobacter strains isolated from the broiler flocks were closely related to a strain isolated from wild bird feces identified in the same farm environment (Hiett et al., 2002).

Other organisms including flies, insects, amoebae, yeasts and molds have been found to be also important routes of horizontal transmission of Campylobacter into poultry houses (AxelssonOlsson et al., 2005; Newell et al., 2011). The presence of Campylobacter cells with amoebae, yeasts and molds allow them to survive longer. A lesser mealworm beetle and their larvae (Alphitobius diaperunus) were identified as important carriers of $C$. jejuni in the poultry facilities. They could transmit C. jejuni not only within batches but also crosscontaminate flocks in the successive rearing cycles (Hazeleger et al., 2008). In addition, microbial eukaryotes may act as a reservoir of Campylobacter in the environment. For example, numerous $C$. jejuni strains are able to invade, replicate, and remain viable inside an amoeba host (i.e., Acanthamoeba polyphaga) (Axelsson-Olsson et al., 2005). Since eukaryotes are usually prevalent in both drinking water systems and microbial biofilms on farms (Snelling et al., 2006), it is highly possible that infected eukaryotes contribute to $C$. jejuni transmission to poultry infrastructure.

There has been a long controversy about whether Campylobacter can be transmitted vertically from one generation of poultry to the other (Cox et al., 2012). One study including 60,000 progeny parent breeders identified a lack of evidence for vertical transmission of Campylobacter to chickens (Callicott et al., 2006). All chickens used in the study were hatched from eggs of Campylobacter-colonized grandparent flocks. However, egg passage can lead to the transmission of fecal bacteria including Campylobacter and subsequently contaminate the shell, shell membrane, and albumen of newly laid and fertile eggs (Cox et al., 2012). This can lead to Campylobacter ingestion after the chicks emerge from their eggs, colonization and spread of Campylobacter in poultry houses. In contrast, vertical transmission is well-established in Salmonella as they contaminate the egg within the reproductive tract before the shell is formed or penetrate the eggshell and invade the yolk of the post-lay egg (Gast and Beard, 1990; Miyamoto et al., 1997; Yang et al., 2001). In addition, Salmonella is the major cause of foodborne outbreaks linked to poultry eggs (Guard-Petter, 2001), while Campylobacter eggassociated outbreaks are extremely rare (Finch and Blake, 1985). A systematic review including a primary set of 4,316 references showed that Campylobacter was rarely isolated from the internal egg contents (Newell et al., 2011), which was also validated by several on-farm studies (Shanker et al., 1986; Van de Giessen et al., 1992; Pearson et al., 1993; Jacobs-Reitsma, 1995; JacobsReitsma et al., 1995; Petersen et al., 2001; Smith et al., 2004; Callicott et al., 2006; Byrd et al., 2007; Kiess et al., 2007). 
Therefore, improving biosecurity systems and applying effective intervention strategies are the key elements to limit the prevalence of Campylobacter in broiler farms.

\section{Chicken Colonization of Campylobacter}

Colonization of Campylobacter in farm chickens occurs usually due to horizontal transmission from the environment, such as via drinking water or animal feed. Once Campylobacter enters the chicken flock, it spreads rapidly and colonizes the intestinal tracts (crap, small intestine, and ceca) of most chickens after one week (Beery et al., 1988; Shanker et al., 1990; Newell et al., 2011). The level of $C$. jejuni inside these niches could be as high as $10^{9}$ cells/gram of intestinal tracts with no symptoms or noticeable harmful effects until slaughtering (Stern et al., 2001). One study reported that $C$. jejuni is not just a commensal bacterium in broiler chickens, but it can cause chronic inflammation, gut tissue damage, and diarrhea (Humphrey et al., 2014). In contrast, four combined and eight individual chicken genotypes showed no difference or negative effect on C. jejuni colonization and proliferation regardless of chicken growth rate or breed (Gormley et al., 2014).

Several factors affect chicken colonization by Campylobacter. These include chicken strain, Campylobacter strain, dosage of viable Campylobacter cells, and seasonality (Newell and Fearnley, 2003). Colonization potential of chickens by some Campylobacter strains could be enhanced by 1,000-folds (Ringoir and Korolik, 2003) or 10,000-folds (Cawthraw et al., 1996) under in-vivo experimental conditions, leading to the challenges to predict the ability of Campylobacter wild strains to colonize chicken flocks in the real commercial farms. There is generally a higher rate of colonization in summer than any other time of the year (Humphery et al., 1993). The colonization level (Wallace et al., 1997) and type of strains (Hudson et al., 1999) are also seasonally dependent. Besides high temperature and humidity, poultry houses require more ventilation during summer, which exposes the birds to more Campylobacter from the outside environment than any other time of the year (Hudson et al., 1999). Even individually caged birds showed a seasonal variation (increased to the peak in late April) in the fecal excretion of $C$. jejuni, suggesting that the surrounding temperature affects bird colonization even under limited conditions of C. jejuni transmission (Doyle, 1984).

Moreover, geographical locations, flock size, and type of the production systems (i.e., organic or conventional) can also influence the colonization of Campylobacter in chicken flocks (Newell and Fearnley, 2003). According to a previous study, up to $100 \%$ of flock were Campylobacter-positive in the case of organic and free-range flocks (Heuer et al., 2001). This is probably due to the exposure to the outside environment and a longer time the birds require to grow to the slaughter size compared to the indoor reared flocks. In the cases where the colonization of Campylobacter identified at species level, C. jejuni was the leading group by colonizing about $90 \%$ of Campylobacter-positive birds. The remaining ones were almost equally colonized by C. coli and C. lari (Uyttendaele et al., 1996). Several studies conducted in Europe suggested that the indoor- grown flocks were primarily colonized by one or two C. jejuni strains. Other studies conducted in North America and Australia showed that several C. jejuni strains usually colonized the indoorgrown flocks. This might be due to different levels of biosecurity standards in different countries as the incidences of C. jejuni colonization can be either due to the exposure to multiple sources consisting of different strains or a single source (e.g., feed or water) consisting of multiple strains. Interestingly, Hald and co-authors reported that C. jejuni colonization was higher in a total of 88 randomly selected poultry flocks raised in Danish farms that fed external grains compared to farms that fed home-grown grains (Hald et al., 2000).

Another important factor of chicken colonization is the adaptation capability and response of Campylobacter strains to the environmental conditions. For example, Gaynor and others identified a remarkable ability of $C$. jejuni to evolve rapidly during storage, culture, and condition passage (Gaynor et al., 2005). The colonization ability of C. jejuni 11168-O strain recognized as an excellent chicken colonizer was compared with C. jejuni 11168-GS clone recognized as a poor chicken colonizer after either aerobic or anaerobic incubation. The anaerobic priming of 11168-GS increased its colonization while the aerobic passaging of $11168-\mathrm{O}$ decreased its colonization compared to their original strains.

Some procedures, such as feed withdrawal and transportation, affect the presence of Campylobacter in live chickens before their arrival into the poultry-processing plants. Feed withdrawal is a common commercial practice that the farmers remove the animal feeds from poultry houses 3 to $18 \mathrm{~h}$ before slaughtering (Byrd et al., 1998). The purpose of this practice is to clear the gastrointestinal tract and reduce the level of fecal materials in the body so as to minimize crosscontamination during poultry processing. Byrd and co-authors showed that feed withdrawal could increase the prevalence of Campylobacter in the crops of broiler chickens at the slaughter age (Byrd et al., 1998). Campylobacter-positive samples increased on average from $25 \%$ to $62.4 \%$ before and after feed withdrawal. The limitation of nutrients in the broiler crops might have resulted in a less diverse and competitive microbiota and subsequently enhanced the growth of Campylobacter. Transportation from farms to processing plants has been identified as a critical harbor for the transmission and colonization of Campylobacter in live birds. This is due to the reuse of contaminated crates for shipping, animal hoarding, and induced-stress during the transportation of live birds from different flocks and/or farms to slaughterhouses (Slader et al., 2002; Newell and Fearnley, 2003). Decontamination methods used for cleaning the reusable shipping crates for transportation was identified to be ineffective (Wedderkopp et al., 2001). Up to 70\% C. jejuni-negative chickens became colonized after exposure to artificially contaminated shipping crates (Clark and Bueschkens, 1988). Whyte and others demonstrated that poultry overcrowding and stress induced during transportation could extensively increase the shedding of Campylobacter in fecal material of broilers and contributed to cross-contamination of their carcasses during processing (Whyte et al., 2001). 
Several studies indicated that C. jejuni acts as a commensal and a super colonizer in chicken cecal microbiota (Awad et al., 2016; Connerton et al., 2018; Ijaz et al., 2018). Awad and coauthors identified that the microbial communities in the luminal and mucosa gut microbiome shifted in a timely manner during the growth of broiler chickens (Awad et al., 2016). A similar finding was observed when the chicken cecal microbiome was analyzed even without any artificial inoculation of C. jejuni (Ijaz et al., 2018). The critical periods for $C$. jejuni colonization ranged from 12 to $28 \mathrm{~d}$ of the broiler chicken age (Awad et al., 2016; Ijaz et al., 2018). Another report showed that C. jejuni appeared in 6day old chicken birds (Connerton et al., 2018). The microbiota variation is usually influenced by the diet and microorganisms present in the surrounding environment, feed, and water (Connerton et al., 2018). For all of these reasons, it is quite challenging to inactivate $C$. jejuni once broiler chickens are colonized. Early prevention of C. jejuni colonization on poultry farms is very important to avoid further colonization. Although no symptom is associated with colonization of $C$. jejuni and $C$. coli in the broiler chickens, the high mortality rate might reflect the colonization prevalence (Powell et al., 2012).

\section{On-Farm Intervention Strategies Against Campylobacter}

Early stage on-farm control of Campylobacter in broiler chickens has gained increasing attention during the last two decades because Campylobacter can effectively colonize chickens from the early days of their lives and remain prevalent at a high level throughout the poultry-processing line (Table 2). The potential of different intervention strategies by using vaccination, phage therapy, bacteriocins, probiotics, fatty acids, and essential oils has been investigated. Each strategy has some advantages and disadvantages (Table 3). For example, numerous bacteriocins (antimicrobial peptides) produced by commensal bacteria from chicken gut microbiota, such as Lactobacillus salivarius, could effectively inactivate Campylobacter under both in-vitro and invivo experimental settings (Svetoch and Stern, 2010). Specifically, the L-1077 bacteriocin was able to reduce $>4 \log \mathrm{CFU} / \mathrm{g}$ of $C$. jejuni in the cecal content. In a recent study, oral administration of three types of bacteriocins from Lactobacillus salivarius (OR7) and Enterococcus faecium (E-760 and E50-52) were used in broiler chickens to investigate the development of resistance by
C. jejuni (Mavri and Smole Možina, 2013). CmeABC multidrug efflux pump in C. jejuni played an important role in intrinsic and acquired resistance against bacteriocins. Thus, combining bacteriocins with an efflux pump inhibitor might synergistically inactivate $C$. jejuni and prevent the development of antimicrobial resistance.

Several studies have investigated the efficacy of Campylobacter phages to either reduce Campylobacter count or prevent their colonization in chicken broilers (Carrillo et al., 2005; Wagenaar et al., 2005; El-Shibiny et al., 2009; Carvalho et al., 2010; Kittler et al., 2013). Some used artificial infections (Carrillo et al., 2005; Wagenaar et al., 2005; El-Shibiny et al., 2009; Kittler et al., 2013) while others used naturally infected birds (Carrillo et al., 2005). One study used an effective colonizer strain of $C$. jejuni and observed a significant reduction by several phages isolated from the same environment of the bacterial host (Wagenaar et al., 2005). Some phages caused up to $3 \mathrm{log}$ reduction within the first $24 \mathrm{~h}$, while others caused about 1 log reduction for up to 30 days at a high Multiplicity of Infection (MOI). The efficacy of Campylobacter phage therapy is not sufficient for a sustainable control of this bacterium. C. jejuni strain and phages used in that study were not isolated from representative samples of chicken farms, meats, or feces. Thus, this model cannot be generalized to be used in a wider therapeutic application in farms. However, the same study showed promising results and indicated that the high dose of phages $(11 \log \mathrm{PFU} / \mathrm{ml})$ did not show any negative impact on the broilers' health.

More studies are required to achieve sustainable benefit of Campylobacter phage therapy. The importance of using phages in the form of cocktail was observed in several studies (Wagenaar et al., 2005; El-Shibiny et al., 2009; Carvalho et al., 2010). Many other factors, such as oral administration route (i.e. phage delivery) and stability of individual phages, play important roles in the overall efficacy of phage therapy application in chicken broilers (Ushanov et al., 2020). For example, different studies indicated that the addition of phages into drinking water can be more effective than oral gavaging, which is not practical for large commercial scale production (Carrillo et al., 2005; Carvalho et al., 2010; Ushanov et al., 2020). However, such application requires more stable phages than others. Altogether, many studies agreed that phage therapy can be

TABLE 2 | Examples of the average prevalence and load of Campylobacter throughout the poultry-processing chain.

\begin{tabular}{|c|c|c|c|}
\hline Stage & Source & Prevalence (\%) and/or average load of Campylobacter & Reference \\
\hline \multirow[t]{2}{*}{ Farm } & Broilers & $87.5 \%, 9 \log$ CFU/g of cecal content $(n=50)$ & (Stern et al., 2001) \\
\hline & Feces & $96.4 \%, 5.16 \log$ CFU/g of fecal content $(n=948)$ & (Stern and Robach, 2003) \\
\hline \multirow[t]{2}{*}{ Transportation } & Caecum & $6.5 \mathrm{log} \mathrm{CFU} / \mathrm{g}$ of cecal content & (Achen et al., 1998) \\
\hline & Feces & $60-100 \%(n=7[10$ flocks $])$ & (Whyte et al., 2001) \\
\hline \multirow[t]{7}{*}{ Plant } & Pre-scald & $77 \%,>6 \log$ CFU/g of feather or skin $(n=40)$ & (Kotula and Pandya, 1995) \\
\hline & Defeathering & $3.9 \log$ CFU/ml of carcasses rinse $(n=24)$ & (Berrang et al., 2000) \\
\hline & Evisceration & 96-100\%, 2.7 log CFU/carcass $(n=48)$ & (Northcutt et al., 2003) \\
\hline & Pre-chill & $98 \%, 4.75 \log \mathrm{CFU} / \mathrm{ml}$ of carcasses rinse $(n=450)$ & (Stern and Robach, 2003) \\
\hline & Post-chill & $84.7 \%, 3.03 \mathrm{log}$ CFU/ml of carcasses rinse $(n=450)$ & (Stern and Robach, 2003) \\
\hline & Pre-wash & $87 \%, 4.78 \log \mathrm{CFU} / \mathrm{ml}$ of carcasses rinse $(n=30$ [ 4 processing plants]) & (Bashor et al., 2004) \\
\hline & Post-wash & $80 \%, 4.30 \log$ CFU/ml of carcasses rinse $(n=30$ [4 processing plants]) & (Bashor et al., 2004) \\
\hline Retail & & $90 \%,>4 \log$ CFU/carcass $(n=552)$ & (Walker et al., 2019) \\
\hline
\end{tabular}


TABLE 3 | Advantages and disadvantages of different prevention and control strategies against Campylobacter in poultry production.

\begin{tabular}{|c|c|c|c|}
\hline Stage & Strategies & Advantage & Disadvantage \\
\hline \multirow[t]{5}{*}{ Farm } & Vaccination & $\begin{array}{l}\text { Preventive and promising (Annamalai et al., 2013; Neal-McKinney } \\
\text { et al., 2014) }\end{array}$ & $\begin{array}{l}\text { Expensive, highly specific, and difficult (Saxena et al., 2013; Kaakoush } \\
\text { et al., 2015) }\end{array}$ \\
\hline & Bacteriophages & $\begin{array}{l}\text { Caused up to } 5 \text { log CFU/g reduction of C. jejuni in cecal content of } \\
\text { commercial broiler flocks (Kittler et al., 2013) }\end{array}$ & $\begin{array}{l}\text { Dilution in the gut over the time and development of resistance (Labrie } \\
\text { et al., 2010; Fischer et al., 2013) }\end{array}$ \\
\hline & Bacteriocins & $\begin{array}{l}\text { Caused }>4 \text { log CFU/g reduction of C. jejuni under in-vitro settings } \\
\text { (Svetoch and Stern, 2010) }\end{array}$ & $\begin{array}{l}\text { Development of antimicrobial resistance by the multidrug efflux pump } \\
\text { CmeABC (Mavri and Smole Možina, 2013) }\end{array}$ \\
\hline & Probiotics & Part of the chicken gut microbiota (Kaakoush et al., 2015) & $\begin{array}{l}\text { Limited reduction of C. jejuni after } 15 \text { d of oral administration (Santini } \\
\text { et al., 2010) }\end{array}$ \\
\hline & $\begin{array}{l}\text { Short chain } \\
\text { fatty acids }\end{array}$ & Ability to invade the gut epithelium cells (Davidson et al., 2005) & $\begin{array}{l}\text { Limited reduction of } C \text {. jejuni under in-vitro settings (Davidson et al., } \\
\text { 2005) }\end{array}$ \\
\hline
\end{tabular}

effective to reduce $C$. jejuni if administrated at a high MOI within 24 to $48 \mathrm{~h}$ prior to slaughter. Phage efficacy can also be improved when phages and hosts are isolated from the same environment. However, this may limit the application of phage therapy to specific poultry farm(s). Therefore, more phages and representative hosts need to be tested.

\section{CAMPYLOBACTER IN POULTRY- PROCESSING PLANTS}

Poultry meat and eggs are important sources of dietary proteins, vitamins, and minerals. Poultry production is an intensively growing industry and chicken meat is one of the most produced meats around the world (Ritchie and Roser, 2017). The annual global amount of produced poultry meats has been rising by 10 -folds within the last 50 years to approximately 102 million tons (Ritchie and Roser, 2017). Chicken is also one of the most sustainable major sources of dietary proteins as the feed conversion ratio (FCR; $\mathrm{kg}$ of feed/kg of edible weight) of chicken meat is only about $40 \%$ of the FCR of beef (Wilkinson, 2011). As a large, diverse and vertically integrated system involving animal farming and food processing, poultry production can be a common source of foodborne outbreaks. Either live poultry or poultry meat are important sources of Campylobacter and other important foodborne pathogens (Kaakoush et al., 2015). Both on-farm and in vivo Campylobacter controls are challenging due to the complexity and diversity of both systems (Tables 2 and $\mathbf{3}$ ). Alternatively, many studies have focused on controlling Campylobacter in the processing facilities.

\section{Campylobacter Survival During Poultry Processing}

Poultry processing is considered as an intensive procedure that requires highly trained personnel. One breach in either sanitation or hygiene practices might end in several cases of foodborne illnesses. Campylobacter enters a processing plant through any potentially contaminated bird(s) at an initial count as many as $10^{9}$ cells/g of cecal content (Beery et al., 1988; Stern et al., 2001). A single processing plant normally receives birds from multiple farms with variations in their ages, sizes, geographical locations, and production and biosecurity systems that increase the chance of Campylobacter contamination. Birds go through different processing steps starting from receiving and hanging until packaging. Processing consists of multiple critical points where Campylobacter starts to occur or increase in chicken carcasses (Table 2). Steps including scalding, defeathering, evisceration, nick removal, inside and outside (or inside-out) washing can all contribute to cross-contamination of Campylobacter in one way or another (Figure 2).

Scalding is a quick immersing of poultry carcasses into warm water $\left(51-64^{\circ} \mathrm{C}\right)$ for a few seconds up to $2 \mathrm{~min}$ so as to loosen the skin follicles for defeathering. Berrang and others investigated the level of Campylobacter, total aerobic microbes, E. coli, and coliform throughout the poultry-processing plant (Berrang and Dickens, 2000). Total aerobic bacteria clearly decreased throughout the processing steps. In contrast, Campylobacter showed the highest recovery (increased from log 1.8 to 3.7 $\mathrm{CFU} / \mathrm{ml}$ of chicken carcass rinse) compared to all the other bacteria after defeathering. Heating of poultry carcasses followed by chilling during the processing steps are essential in assisting practices for effective defeathering. However, this temperature fluctuation creates several challenges to control microorganisms including Campylobacter. For example, skin follicles remain open after scalding that allows bacteria to penetrate the skin and accumulate inside the follicles. Moreover, the follicles close again during chilling, making the poultry decontamination to be highly challenging. In addition, a large shift appears in the native skin microbiome of chicken (Thomas and McMeekin, 1980). The predominately Gram-positive skin microbiota (e.g., Micrococcus) is usually detached and replaced by a population mixture consisting of a majority of Gram-negative bacteria. However, the alteration of chicken meat microbiome during processing varies based on multiple factors, including geographical location, season, and bird-to-bird. One common factor is that scalding liquidizes some fats on the skin that became part of chicken juice and other surrounding fluids. The liquid fat solidifies again during the chilling step and creates a lipid film on the surface of chicken meat. Both scanning electron microscopy and transmission electron microscopy showed that scalding and defeathering scraped off the epidermis cells of chicken skin that became smoother and less hydrophobic than normal after processing (Thomas and McMeekin, 1980). The bacterial contaminants were identified within a protective fluid film formed both on the surface and inside deep channels of chicken skin after chilling, which makes microorganisms in chicken meat unapproachable by the antimicrobial agents. 


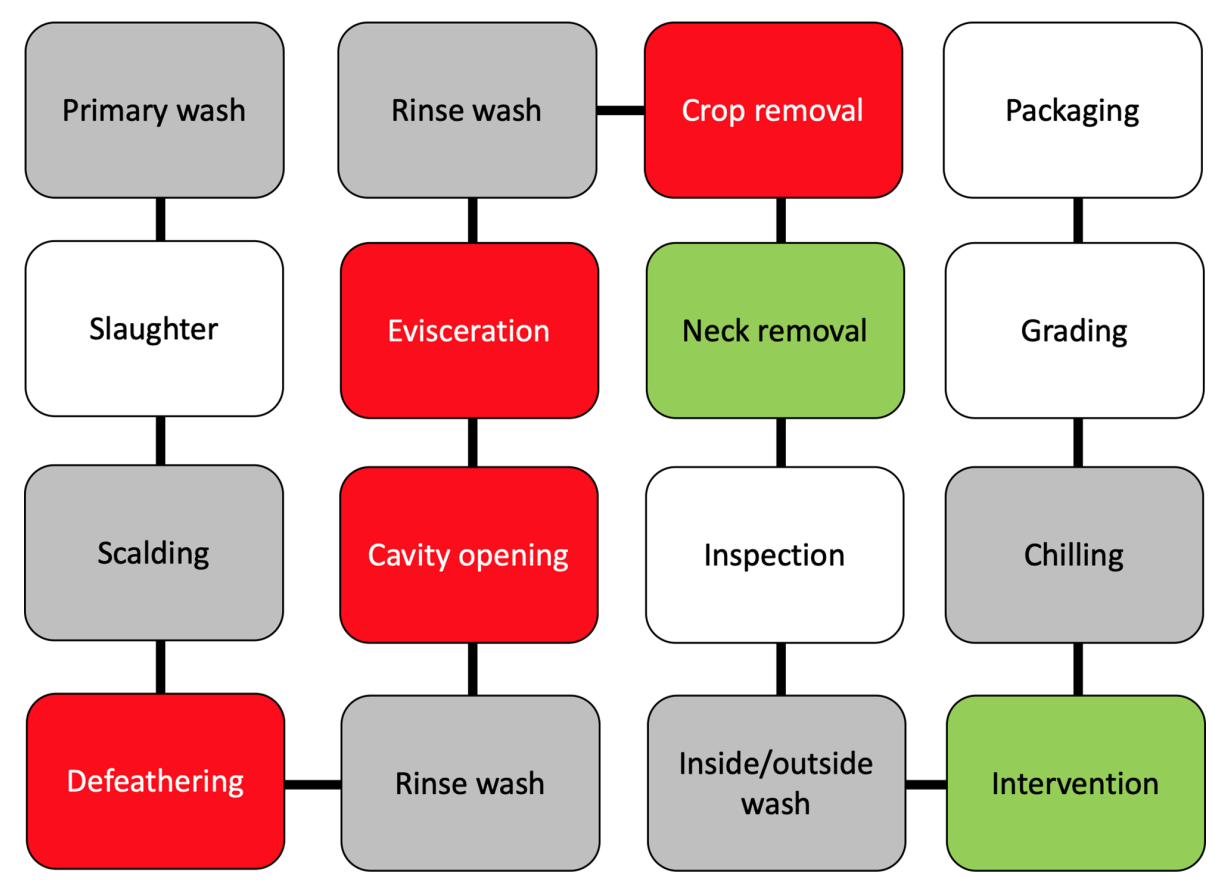

FIGURE 2 | A schematic diagram of raw chicken processing steps. The gray boxes reflect steps that can enhance cross-contamination, the red boxes reflect steps where cross-contamination usually occurs, while green boxes reflect steps that contribute to the mitigation of Campylobacter.

Moreover, evisceration is one of the most critical steps of crosscontamination. Colonized gastrointestinal tract of poultry birds carries a large number of Campylobacter bacteria that can spread in a wide range, especially in the case of gut leakage. Many in-plant studies confirmed that the number of Campylobacter-positive carcasses significantly increased after this process (Berrang et al., 2001; Northcutt et al., 2003; Keener et al., 2004). For example, Campylobacter-positive chicken thighs and breasts separately increased from $0 \%$ to $90 \%$ at a level between 2 and $3 \log \mathrm{CFU} / \mathrm{g}$ after evisceration (Berrang et al., 2001). Another study identified that Campylobacter contamination level was higher on the breast meat than the thigh meat or drumstick (Kotula and Pandya, 1995). Leaking of Campylobacter from the gut during evisceration can contaminate the lower half of the carcasses (breast and neck) more than the upper half (thighs and drumstick) as the birds are always hanged upside-down by the feet. The hanging necks of carcasses were also frequently determined to be Campylobacter-positive (Kotula and Pandya, 1995).

Poultry carcasses require rapid cooling to prevent the growth of microorganisms after evisceration. Chilling and antimicrobial treatment are usually combined in many processing plants to save energy and rapidly inhibit bacterial growth by washing the carcasses with cold chlorinated water (Keener et al., 2004). Poultry carcasses are usually washed by dipping or spraying using chlorinated water to remove blood, tissue, fragments, and contamination after evisceration. Dipping can cross-contaminate carcasses under commercial processing conditions especially when processing a large number of birds at the time (Bailey et al., 1987; Bilgili et al., 2002; Demirok et al., 2013). In contrast, spray washers tend to reduce the level of cross-contamination on the chicken meat (Keener et al., 2004; Demirok et al., 2013). Several options of spraying systems for poultry carcasses have been used in poultry industry, including brush, cabinet, and inside-out washing systems (Keener et al., 2004). The brush washing system is similar to a car washer where many rubber fingers are used with the aid of water to remove debris and wash the carcasses from the outside. The cabinet washing system contains multiple sprayers in an enclosed system to wash the outside of the carcasses. Inside-out system is a similar enclosed spraying system but used for both external and internal washing at the same time. The machine rotates the carcasses and sprays them from the outside, while probes of single sprayers enter the intestinal cavities of carcasses to wash them from the inside. Many inside-out washing machines spray water at the pressure level between 40 and 180 psi to remove visible fecal contamination and fragments (Keener et al., 2004). Chlorine concentration ranged from 20 to $50 \mathrm{mg} / \mathrm{L}$ and water consumption ranged from 100 to $200 \mathrm{~L} / \mathrm{min}$.

\section{Antimicrobial Treatments for Poultry Processing}

Many laboratory-scale experiments showed that the approved antimicrobials such as acidified sodium, chlorite, cetylpyridinium, chlorine, chlorine dioxide, peroxyacetic acid, and trisodium phosphate could cause up to 5 log reduction of Campylobacter in chicken meat (Table 3). However, in-plant poultry washers have limited effect on inactivating Campylobacter in chicken meat regardless of the efficacy of antimicrobials, water temperature, or 
washing system. This could be due to several factors including the presence of large molecules in chicken meat (e.g., proteins and lipids) and Campylobacter in chicken skin due to changes induced by processing, sensitivity of chicken skin to heat, oxidation and discoloration, initial microbial load of carcasses, number of processed carcasses per min, interaction or masking of antimicrobials (e.g., chlorine) by organic materials in the processing water, water quality and survival of Campylobacter in recycled processing water, poor sanitation, accumulation of lipids, fecal materials, and/or organics at any point through the processing line. It is worth mentioning that there is no effective critical control (i.e., killing) point in processing raw chicken similar to that of the pasteurization step for milk processing (Tresse et al., 2017).

\section{Current Situation of Raw Poultry Product Safety}

The prevalence of Campylobacter in poultry products is clearly a major food safety challenge for many years. It is important to target chicken as a critical food vehicle of $C$. jejuni due to the high rate of contamination. More on-farm and in-plant control strategies became available in the recent years, but these strategies need improvement to enable effective inactivation of Campylobacter at an early stage or in chicken end-products. In 2015, the United State Department of Agriculture, the Food Safety and Inspection Service agency (USDA-FSIS) established a new Campylobacter and Salmonella performance standard for the contaminated poultry products, raw chicken parts (e.g., breasts, thighs, wings), and not ready-to-eat (NRTE) poultry products (Crim et al., 2015). For example, 8 out of 51 Campylobacter-positive broiler carcasses is the maximum acceptable number of randomly tested samples. In 2018, new antimicrobial agents have been approved by the USDA-FSIS to be used in washing poultry carcasses during processing. These include peroxyacetic acid (a mixture of hydrogen peroxide and acetic acid), a mixture of calcium chloride, calcium hypochlorite, sodium chloride, calcium hydroxide, calcium carbonate, sodium triphosphate, and a combination of calcium chloride with sodium bisulfate (Service, 2018). Although Campylobacter can be reduced to some extent by antimicrobials, they still might not be reduced to a safe level as only a few hundred cells might cause human illnesses (Black et al., 1988; Hara-Kudo and Takatori, 2011). In addition, in-plant antimicrobial treatment requires intensive amount of water to wash chicken carcasses. For example, a medium size poultry-processing plant spends annually $\$ 0.5$ to 1 million USD on average on water consumption for washing chicken carcasses and surfaces (Jackson, 1999), but Campylobacter reduction is still insufficient.

\section{ALTERNATIVE STRATEGIES TO CONTROL C. JEJUNI IN AGRI-FOODS}

\section{Plant-Based Antimicrobials}

Plant-derived compounds have been used for centuries in medicine, perfumery, cosmetics or being added to foods as oils, herbs or spices (Hyldgaard et al., 2012). For example, herbs and essential oils were initially used in medicine due to their antimicrobial, anti-inflammatory, or antioxidant effects, then their application expanded in agri-foods in the $19^{\text {th }}$ century for their aroma and flavors. These antimicrobials are important secondary metabolites that play major roles in plant defense systems to protect them from microbial infections (Tajkarimi et al., 2010). It was estimated that $\sim 3,000$ essential oils have been identified and $\sim 300$ are commercially available for flavoring, fragments, or cosmetics (Van de Braak and Leijten, 1999). In addition, essential oils can act as growth promoters in farm animals similar to antibiotics (Brenes and Roura, 2010; Ahmadifar et al., 2011). A histology study showed that feeding different plant extracts to chicken broilers increased the thickness of the mucus layer in the glandular stomach and jejunum (Jamroz et al., 2006). These changes were associated with a large shift in gut microbiota that could hypothetically promote the growth of birds.

Cinnamon is one of the earliest spices used in human history and cinnamon oil is among the most studied essential oils due to its high antimicrobial potency (Ravindran et al., 2003). The genus Cinnamomum consists of $\sim 250$ different species. C. verum and $C$. cassia are the most known and used herbal medicines or spices. These plants are the main natural sources of cinnamon. Cinnamon oil consists of several major antimicrobial compounds, including cinnamaldehyde (7090\%), 1-linalool, p-cymene, and eugenol (Davidson et al., 2005). Aldehyde groups are reactive organic compounds that can crosslink covalently with proteins and nucleic acids through amine groups. Therefore, the mode of action of cinnamaldehyde is inconclusive. Several mechanisms can occur depending on the bioavailability and concentration of the system (Hyldgaard et al., 2012). For example, cytokinesis can be inhibited due to the inhibition of different enzymes by cinnamaldehyde at a low concentration. ATPase inhibition occurs at the sub-lethal concentration, while the alteration of fatty acid composition of cell membrane, cell leakage and cell death occur at the lethal concentration.

In comparison, curcumin is the major active compound of the rhizome of turmeric (Curcuma longa). This golden spice is a phenolic pigment responsible for the yellow color of turmeric. Numerous studies have shown that curcumin can effectively inactivate both Gram-negative and Gram-positive bacteria (Rudrappa and Bais, 2008; Kaur et al., 2010; Tyagi et al., 2015). However, limited studies have investigated the antimicrobial mechanism of curcumin. Blocking the assembly of the FtsZ protein essential for forming the FtsZ ring (i.e., $\mathrm{Z}$ ring) to initiate cell division in bacteria was identified to be the mode of action against Bacillus subtilis and E. coli (Kaur et al., 2010). In contrast, curcumin has been found to attenuate several virulence factors, including quorum sensing and biofilm formation in $P$. aeruginosa (Rudrappa and Bais, 2008). A recent study examined the membrane permeability of S. aureus, Enterococcus faecalis, E. coli, and $P$. aeruginosa after being treated with curcumin (Tyagi et al., 2015). A steady-state fluorescence and flow cytometry analyses showed uptake in the extracellular propidium iodide 
(only enters intact bacterial cells by a permeabilizing agent) and leakage of calcein (only leak out of bacterial cells if there is membrane damage due to cell wall membrane damage) in both Gram-positive Gram-negative bacteria. Antimicrobial mechanism of curcumin is different depending on the bacteria studied and the assays used (Han et al., 2006; De et al., 2009; Kaur et al., 2010; Tyagi et al., 2015). More studies are still needed to confirm the antimicrobial mechanism(s) of the action of curcumin.

To the best of our knowledge, the specific antimicrobial mechanism of curcumin against Campylobacter has not been investigated. The effect of curcumin against Helicobacter pylori, a highly relevant bacterium to Campylobacter, has been repeatedly confirmed in several studies (Di Mario et al., 2007; Zaidi et al., 2009; Sarkar et al., 2016; Vetvicka et al., 2016). One study of using a high-throughput screening of 5,000 chemical compounds discovered that the inhibition of $H$. pylori by curcumin was due to the inhibition of shikimate pathway (Han et al., 2006). This pathway is essential for the synthesis of aromatic amino acids (e.g., phenylalanine, tryptophan, and tyrosine) in bacteria, fungi, and higher plants, but not in mammals. Targeting this particular pathway makes curcumin a very safe antimicrobial agent for human consumption. In fact, curcumin showed no toxicity on human health even used at a level as high as 8,000 mg per day (Cheng et al., 2001; Lao et al., 2006). In addition, the antimicrobial activity of curcumin against $H$. pylori in vitro $(65$ clinical isolates) and in vivo during infections in mice were examined. The minimum inhibitory concentration (MIC) of curcumin ranged from 5 to $50 \mu \mathrm{g} / \mathrm{ml}$ regardless of genetic variation of the tested Helicobacter strains. Curcumin not only inactivated $H$. pylori during infection but also reduced the gastric damage induced by $H$. pylori infection to almost a normal state. Although limited studies have identified the antimicrobial mechanism of curcumin, available evidence shows its great potential for preventing and treating bacterial contaminations and infections.

\section{Metal Oxide Nanoparticles}

Novel applications of nanotechnology and nanomaterials have gained great attention in the recent years. For example, the applications of metal oxide nanoparticles (e.g., $\mathrm{Al}_{2} \mathrm{O}_{3}, \mathrm{TiO}_{2}$, and $\mathrm{ZnO}$ NPs) could inactivate several foodborne pathogens in a variety of agri-food systems (Fernández et al., 2009; Akbar and Anal, 2014; Panea et al., 2014). ZnO was identified to be more effective than other metal oxides (e.g., $\mathrm{CuO}$ and $\mathrm{Fe}_{2} \mathrm{O}_{3}$ ) against both Gram-negative and Gram-positive bacteria (Azam et al., 2012). In addition, $\mathrm{ZnO}$ NPs was more effective against $C$. jejuni than other Gram-negative bacteria including E. coli O157: $\mathrm{H} 7$ and S. enterica (Xie et al., 2011). The direct contact of $\mathrm{ZnO}$ NPs (positively charged) with bacterial cell wall (negatively charged) by electrostatic force leads to destabilization and disruption of bacterial outer cell membrane. In addition, semiconductive property of $\mathrm{ZnO}$ allows the generation of reactive oxygen species that can attack different cytoplasmic and extra-cytoplasmic targets after the binding (Sirelkhatim et al., 2015).

\section{Synergism}

Antimicrobial combinations have been used since the earliest days of the recorded history to treat illnesses and reduce sufferings (Chou, 2006). Therapeutic use of traditional Chinese herbs is a prime example. Indeed, antibiotic is one of the most important drug discoveries in the modern medicine. However, the emergence of antibiotic resistance to most available antibiotics became a serious public health concern in the recent years and near future (de Kraker et al., 2016). A synergistic combination of antimicrobials can minimize some of the disadvantages associated with the use of antimicrobials, such as the development of bacterial resistance, high dosage, and limited effect (Chou, 2006). Antimicrobial combination has been extensively studied to inactivate some highly challenging bacterial and viral infections including methicillin-resistant Staphylococcus aureus infection (An et al., 2011) and human immunodeficiency virus infection (Gaibani et al., 2019).

Synergism is defined as an effect that is greater than the sum of multiple individual effects. Many approaches, hypotheses, methodologies, and models have been used to study the synergism in different fields, including microbiology, pharmacology and enzymology (Chou, 2006). The definition of synergism is a very controversial topic due to the complexity of biological systems and some possible mathematical errors or pitfalls in the combinatorial studies. Some important concepts such as the difference between synergism and enhancement or potentiation are not fully clear. For example, if antimicrobial A has a quantifiable effect (e.g., 10\%), while antimicrobial B has no effect (i.e., 0\%), and their combination produces an effect greater than antimicrobial A (e.g., 20\%), then this is considered as an enhancement or potentiation, but not a synergistic interaction. In contrast, synergism is an effect greater than the sum of multiple quantifiable effects (e.g., $10 \%+10 \%=30 \%$ ). In addition, the additive effect has always to be less than $100 \%$. For example, if antimicrobial A and B each affects 20\%, the additive effect is not simply $40 \%$ because if each antimicrobial produces $70 \%$ effect the combined effect cannot be $140 \%$. Chou and Talalay reported the fractional product equation to solve this issue $[(1-0.7)(1-0.7)=0.09]$ where the additive effect can never exceed $100 \%$ (Chou and Talalay, 1984).

\section{Methods for Identifying Antimicrobial Synergism}

Three methods are most used in antimicrobial combination studies. These include the disk diffusion method, time killing method and fractional inhibitory concentration index method (FICI) (Odds, 2003; Zhou et al., 2016). Disk diffusion method is a simple visual test that relies on comparing bacterial inhibition zones of diffused (single and combined) antimicrobial agents in the agar plates. Time killing method shows how a bacterial population responds to the antimicrobial treatment at different time intervals in either broth or agar medium. It relies on monitoring the antimicrobial effect of single and combined antimicrobials by calculating the log reduction of lethal and sub-lethal concentrations over time. For example, if antimicrobial A caused $1 \log$ reduction and antimicrobial B caused $1 \log$ reduction, then the additive effect would be $2 \log$ 
reduction. In this case, synergism would require effect greater than $2 \log$ reduction (e.g., $1+1=3$ ). This method is laborintensive and time-consuming. Thus, a few concentrations of antimicrobials are usually used and combined at a fixed ratio. In contrast, the FICI method (also called microdilution checkerboard) shows a clear visualization of positive/negative inhibitory interactions of multiple ratios of combined antimicrobials. It relies on constructing two antimicrobial combinations in a two-dimension array (e.g., 96-well plate) and comparing the MICs of single and combined treatments. Synergy requires at least a four-fold reduction in the MIC of both antimicrobials combined (i.e., FICI value of $\leq 0.5$ ). The FICI method gained more popularity in the recent years as it is more restricted in identifying synergism, more comprehensive, and easier to construct and interpret than other methods.

\section{Types and Mechanisms of Antimicrobial Synergism}

Different types of antimicrobial interactions can occur between antimicrobials depending on their origins and individual mechanisms. It is common to observe synergism between antimicrobials of different mechanisms and different targets (Jia et al., 2009; Oh et al., 2015). For example, combining efflux pump inhibitor(s) with an intracellular antimicrobial(s) can synergize to inactivate microorganisms that use efflux pumps to remove antimicrobials due to antimicrobial accumulation inside the cells (Oh et al., 2015). In addition, antimicrobials may synergize due to the complementary or facilitating collective actions (Jia et al., 2009). Although different antimicrobials may have different targets and mechanisms, they might have overlapping pathways at the molecular level. More importantly, synergism can be used to increase bacterial antibiotic susceptibility.

\section{Applications of Synergism}

Bacteria develop resistance to antibiotics via different mechanisms (Mavri and Smole Možina, 2013). These include the modification of a receptor or active site of the antibiotic target to prevent or reduce binding, production of enzymes that directly destruct or modify the antibiotics, and/or reducing the accumulation inside the cells by decreasing the outer cell membrane permeability or pumping out the antibiotics using efflux pumps. One of the best applications for antimicrobial synergism is to be against tolerant and/or resistant pathogens that require more than single or additive treatments. For example, Augmetin ${ }^{\circledR}$ is a common commercial antibiotic that consists of a combination of clavulanate acid and amoxicillin to inactivate different pathogens, including $\beta$-lactam resistant bacteria (12). The combination of clarithromycin and amoxicillin is part of the standard therapy for $H$. pylori stomach infections (11).

Plant-based antimicrobials are a great source of new alternative antimicrobials. Many recent studies showed that plant-based antimicrobials (e.g., phenolic compounds) synergize with antibiotics (e.g., amikacin, ceftriaxone, cephradine, methicillin, imipenem) (Oh and Jeon, 2015) or metal oxide nanoparticles (Hemaiswarya and Doble, 2010) against various microbes. $\mathrm{Oh}$ and Jeon reported synergistic interactions of several phenolic compounds (e.g., gallic acid and taxifolin) in combination with ciprofloxacin or erythromycin against fluoroquinolones- and macrolidesresistant C. jejuni isolates (Oh and Jeon, 2015). Phenolic compounds increased membrane permeability as determined by measuring the intracellular uptake of $1-N$-phenylethylamine. As a result, accumulation of both antibiotics increased substantially inside the bacterial cells. Further testing showed that phenolic compounds increased 1-N-phenylethylamine accumulation in an isogenic (knockout) $c m e B$ mutant more than that in a wild type $C$. jejuni strain. In addition, the expression level of CmeABC multidrug efflux pump was reduced by several phenolic compounds (i.e., gallic acid and taxifolin). These findings indicated that phenolic compounds increased the influx rate and decreased the efflux rate of antibiotics.

\section{Active Packaging}

Food packaging is one of the last steps in food processing to ensure that the food products are contained and delivered in the best condition. Packaging materials and/or the atmospheric condition inside the packaging are used to protect the foods from microbial growth, pathogen contamination, physical damage, chemical degradation, or other effects from the environment. Most of the commercially applied packaging technologies aim to preserve food quality and extend the shelf life of food products. Moreover, data regarding the use of active packaging to control foodborne pathogens in potentially contaminated and high-risk foods is still limited compared to those for spoilage bacteria. For example, modified atmospheric packaging (MAP) was extensively studied for the control of spoilage microorganisms in a variety of food products, such as raw meats, fresh produce, and seafood products (McMillin, 2008). In addition, recent technologies and intervention strategies that are used in food processing allow food packaging to be a suitable component of hurdle technology. Such approach might overcome the challenge of controlling the survival of frequently isolated pathogens from commercially available raw meats, such as $C$. jejuni in chicken, $V$. parahaemolyticus in seafood, and pathogenic E. coli in beef.

Fresh poultry, raw meats, and seafoods are considered as high-risk and highly perishable foods. Foods of animal origins including raw milk, raw cheese, and raw meats have a high content of moisture and nutrients. These factors form an ideal environment for rapid growth and/or long survival of many microorganisms, including both spoilage and pathogenic bacteria. Different bacteria have been commonly isolated from fresh chicken meats after processing. These include Micrococcus, Gram-positive rods, Cytophaga-Flavobacterium, Pseudomonas, and Enterobacteriaceae (Thomas and McMeekin, 1980). Thomas and McMeekin identified that poultry carcasses originally carried Micrococcus as a part of the skin microbiome, but contamination with the psychrotrophic Pseudomonas appeared after processing (Thomas and McMeekin, 1980). A whole-genome sequencing analysis showed that the Firmicutes (mainly Gram-positive) were the most abundant bacterial group based on the phyla level of raw chicken meat after processing (Kim et al., 2017).

Campylobacter and Salmonella are the most frequently isolated human pathogens from poultry products at the retail level (Rouger et al., 2017). No correlation was 
established between the prevalence of these two poultryassociated pathogens in chicken carcasses collected from 58 slaughterhouses during a 12-month period in France (Hue et al., 2011). Moreover, no correlation was established between the microbial load (i.e., total aerobic count, Enterobacteriaceae, and coliform) and the prevalence of Campylobacter in chicken and turkey fresh meat cuts (Fontanot et al., 2014). Thus, the prevalence of Campylobacter in poultry end products is random and unpredictable because transmission in farms and crosscontamination during processing can occur at any point, which is not always associated with any other microbial indicators. The large size of poultry industry and production scale makes the detection of Campylobacter more challenging in these products. Both Campylobacter and Salmonella can originally occur at a high level (up to $10^{8} \mathrm{CFU} / \mathrm{g}$ ) in the gastrointestinal tract of birds, but their prevalence in poultry meat varies depending on the cross-contamination incidents. A positive correlation was identified between Campylobacter level in chicken caeca and the end products (Hue et al., 2011). C. jejuni and $C$. coli were equally prevalent in chicken caeca, but C. jejuni was the most frequently isolated one from processed carcasses. These findings highlight the difficulty of preventing the presence of C. jejuni in poultry end products from Campylobacterpositive carcasses.

Bioactive packaging is an effective method for the control of common foodborne pathogens in foods, including raw meat and fresh produce. It can be used for quality preservation purposes to limit the growth of spoilage microflora, or reduce the prevalence of foodborne pathogens in high-risk foods (Panea et al., 2014; Hakeem et al., 2020). For example, different coliphages and Listeria phages were immobilized on active packaging materials to control E. coli $\mathrm{O} 104: \mathrm{H} 4$ in alfalfa sprouts during germination and L. monocytogenes in cantaloupes during cold storage (Lone et al., 2016). One major issue is that most phages are not stable under dehydration condition, which limit their applications in bioactive packaging (Anany et al., 2011). Thus, many studies have used phages in the absorbing pads that are usually placed under fresh foods to absorb moisture and fluids. This can maintain the quality and freshness of fresh foods and protect phages from desiccation at the same time (Hakeem et al., 2020).

\section{REFERENCES}

Achen, M., Morishita, T. Y., and Ley, E. C. (1998). Shedding and colonization of Campylobacter jejuni in broilers from day-of-hatch to slaughter age. Avian Diseases 42, 732-737. doi: 10.2307/1592708

Acheson, D., and Allos, B. M. (2001). Campylobacter jejuni infections: update on emerging issues and trends. Clin. Infect. Diseases 32, 1201-1206. doi: 10.1086/ 319760

Ahmadifar, E., Falahatkar, B., and Akrami, R. (2011). Effects of dietary thymolcarvacrol on growth performance, hematological parameters and tissue composition of juvenile rainbow trout, Oncorhynchus mykiss. J. Appl. Ichthyol. 27, 1057-1060. doi: 10.1111/j.1439-0426.2011.01763.x

Akbar, A., and Anal, A. K. (2014). Zinc oxide nanoparticles loaded active packaging, a challenge study against Salmonella typhimurium and Staphylococcus aureus in ready-to-eat poultry meat. Food Control 38, 88-95. doi: 10.1016/j.foodcont.2013.09.065

\section{CONCLUDING REMARKS}

Campylobacter is one of the leading foodborne pathogens responsible for human gastroenteritis. No effective control method is available to prevent Campylobacter contamination either in poultry farms or poultry-processing plants. Both poultry farms and processing systems are complex and require intensive operations. In addition, the use of antibiotics as growth promoters was banned to limit antibiotic resistance in different countries. The efficacy of many approved antimicrobials on the reduction of Campylobacter in poultry-processing plants is limited. For all of these aforementioned factors, new generations of antimicrobials including novel synergistic antimicrobial combination are required for Campylobacter control and prevention in the agro-ecosystem. Considering the challenges in controlling $C$. jejuni in poultry farms and processing plants, innovative antimicrobial packaging to reduce C. jejuni in raw chicken meat at the retail level is needed. Many new effective approaches are available for the control C. jejuni to enhance the safety of the end products. These include bioactive packaging of bacteriophages or nanoparticles as well as the use of synergistic combinations of antimicrobials to maximize the advantages and minimize disadvantages associated with their uses.

\section{AUTHOR CONTRIBUTIONS}

$\mathrm{MH}$ wrote the manuscript. XL supervised, reviewed, and edited the manuscript. All authors contributed to the article and approved the submitted version.

\section{FUNDING}

XL was supported by Genome British Columbia/Genome Canada [SIP021] and the Natural Sciences and Engineering Research Council of Canada in the form of Discovery Grant (NSERC RGPIN-2019-03960) and Discovery Accelerator Grant (PGPAS-2019-00024). MH received a 5-year scholarship (20152020) from King Saud University.

Al-Nehlawi, A., Saldo, J., Vega, L. F., and Guri, S. (2013). Effect of high carbon dioxide atmosphere packaging and soluble gas stabilization pre-treatment on the shelf-life and quality of chicken drumsticks. Meat Sci. 94, 1-8. doi: 10.1016/ j.meatsci.2012.12.008

An, J., Zuo, G. Y., Hao, X. Y., Wang, G. C., and Li, Z. S. (2011). Antibacterial and synergy of a flavanonol rhamnoside with antibiotics against clinical isolates of methicillin-resistant Staphylococcus aureus (MRSA). Phytomedicine 18, 990993. doi: 10.1016/j.phymed.2011.02.013

Anany, H., Chen, W., Pelton, R., and Griffiths, M. W. (2011). Biocontrol of Listeria monocytogenes and Escherichia coli O157: H7 in meat by using phages immobilized on modified cellulose membranes. Appl. Environ. Microbiol. 77, 6379-6387. doi: 10.1128/AEM.05493-11

Annamalai, T., Pina-Mimbela, R., Kumar, A., Binjawadagi, B., Liu, Z., Renukaradhya, G. J., et al. (2013). Evaluation of nanoparticle-encapsulated outer membrane proteins for the control of Campylobacter jejuni colonization in chickens. Poultry Sci. 92, 2201-2211. doi: 10.3382/ps.2012-03004 
Awad, W. A., Mann, E., Dzieciol, M., Hess, C., Schmitz-Esser, S., Wagner, M., et al. (2016). Age-related differences in the luminal and mucosa-associated gut microbiome of broiler chickens and shifts associated with Campylobacter jejuni infection. Front. Cell. Infect. Microbiol. 6:3389/fcimb.2016.00154:154. doi: $10.3389 /$ fcimb.2016.00154

Axelsson-Olsson, D., Waldenström, J., Broman, T., Olsen, B., and Holmberg, M. (2005). Protozoan Acanthamoeba polyphaga as a potential reservoir for Campylobacter jejuni. Appl. Environ. Microbiol. 71, 987-992. doi: 10.1128/ AEM.71.2.987-992.2005

Azam, A., Ahmed, A. S., Oves, M., Khan, M. S., Habib, S. S., and Memic, A. (2012). Antimicrobial activity of metal oxide nanoparticles against Gram-positive and Gram-negative bacteria: a comparative study. Int. J. Nanomed. 7, 6003. doi: 10.2147/IJN.S35347

Bacon, D. J., Alm, R. A., Hu, L., Hickey, T. E., Ewing, C. P., Batchelor, R. A., et al. (2002). DNA sequence and mutational analyses of the pVir plasmid of. Campylobacter jejuni 70, 6242-6250. doi: 10.1128/IAI.70.11.6242-6250.2002

Bailey, J. S., Thomson, J. E., and Cox, N. A. (1987). Contamination of poultry during processing. Acad. Press Orlando FL.

Bashor, M. P., Curtis, P. A., Keener, K. M., Sheldon, B. W., Kathariou, S., and Osborne, J. A. (2004). Effects of carcass washers on Campylobacter contamination in large broiler processing plants. Poultry Sci. 83, 1232-1239. doi: $10.1093 / \mathrm{ps} / 83.7 .1232$

Batz, M. B., Hoffmann, S., and Morris Jr., J. G. (2012). Ranking the disease burden of 14 pathogens in food sources in the United States using attribution data from outbreak investigations and expert elicitation. J. Food Protect. 75, 12781291. doi: 10.4315/0362-028X.JFP-11-418

BC Center for Disease Control (2017). British Columbia annual summary of reportable diseases. British Columbia Center for Disease Control. Available at: http://www.bccdc.ca/resource-gallery/Documents/Statistics and Research/ Statistics and Reports/Epid/Annual Reports/2017CDAnnualReportFinal.pdf.

Beery, J. T., Hugdahl, M. B., and Doyle, M. P. (1988). Colonization of gastrointestinal tracts of chicks by. Campylobacter jejuni. Appl. Environ. Microbiol. 54, 2365-2370.

Berrang, M. E., and Dickens, J. A. (2000). Presence and level of Campylobacter spp. on broiler carcasses throughout the processing plant. J. Appl. Poultry Res. 9, 43-47. doi: 10.1093/japr/9.1.43

Berrang, M. E., Dickens, J. A., and Musgrove, M. T. (2000). Effects of hot water application after defeathering on the levels of Campylobacter, coliform bacteria, and Escherichia coli on broiler carcasses. Poultry Sci. 79, 1689-1693. doi: 10.1093/ps/79.11.1689

Berrang, M. E., Ladely, S. R., and Buhr, R. J. (2001). Presence and level of Campylobacter, coliforms, Escherichia coli, and total aerobic bacteria recovered from broiler parts with and without skin. J. Food Protect. 64, 184-188. doi: 10.4315/0362-028x-64.2.184

Bessède, E., Lehours, P., Labadi, L., Bakiri, S., and Mégraud, F. (2014). Comparison of characteristics of patients infected by Campylobacter jejuni, Campylobacter coli, and Campylobacter fetus. J. Clin. Microbiol. 52, 328-330. doi: 10.1128/ JCM.03029-13

Bilgili, S. F., Waldroup, A. L., Zelenka, D., and Marion, J. E. (2002). Visible ingesta on prechill carcasses does not affect the microbiological quality of broiler carcasses after immersion chilling. J. Appl. Poultry Res. 11, 233-238. doi: $10.1093 /$ japr/11.3.233

Black, R. E., Levine, M. M., Clements, M., Hughes, T. P., and Blaser, M. J. (1988). Experimental Campylobacter jejuni infection in humans. J. Infect. Diseases 157, 472-479. doi: 10.1093/infdis/157.3.472

Blankenship, L. C., and Craven, S. E. (1982). Campylobacter jejuni survival in chicken meat as a function of temperature. Appl. Environ. Microbiol. 44, 88-92.

Brás, A. M., Chatterjee, S., Wren, B. W., Newell, D. G., and Ketley, J. M. (1999). A novel Campylobacter jejuni two-component regulatory system important for temperature-dependent growth and colonization. J. Bacteriol. 181, 3298-3302. doi: 10.1128/JB.181.10.3298-3302.1999

Brenes, A., and Roura, E. (2010). Essential oils in poultry nutrition: Main effects and modes of action. Anim. Anim. Feed Sci. Technol. 158, 1-14. doi: 10.1016/ j.anifeedsci.2010.03.007

Byrd, J. A., Corrier, D. E., Hume, M. E., Bailey, R. H., Stanker, L. H., and Hargis, B. M. (1998). Incidence of Campylobacter in crops of preharvest market-age broiler chickens. Poultry Sci. 77, 1303-1305. doi: 10.1093/ps/77.9.1303
Byrd, J., Bailey, R. H., Wills, R., and Nisbet, D. (2007). Recovery of Campylobacter from commercial broiler hatchery trayliners. Poultry Sci. 86, 26-29. doi: $10.1093 / \mathrm{ps} / 86.1 .26$

Callicott, K. A., Friðriksdóttir, V., Reiersen, J., Lowman, R., Bisaillon, J.-R., Gunnarsson, E., et al. (2006). Lack of evidence for vertical transmission of Campylobacter spp. in chickens. Appl. Environ. Microbiol. 72, 5794-5798. doi: 10.1128/AEM.02991-05

Carrillo, C. L., Atterbury, R. J., El-Shibiny, A., Connerton, P. L., Dillon, E., Scott, A., et al. (2005). Bacteriophage therapy to reduce Campylobacter jejuni colonization of broiler chickens. Appl. Environ. Microbiol. 11, 6554-6563. doi: 10.1128/ AEM.71.11.6554-6563.2005

Carvalho, C. M., Gannon, B. W., Halfhide, D. E., Santos, S. B., Hayes, C. M., Roe, J. M., et al (2010). The in-vivo efficacy of two administration routes of a phage cocktail to reduce numbers of Campylobacter coli and Campylobacter jejuni in chickens. BMC Microbiol. 11, 232. doi: 10.1186/ 1471-2180-10-232

Casanova, C., Schweiger, A., von Steiger, N., Droz, S., and Marschall, J. (2015). Campylobacter concisus pseudo-outbreak caused by improved culture conditions. J. Clin. Microbiol. 53, 660-662. doi: 10.1128/JCM.02608-14

Cawthraw, S. A., Wassenaar, T. M., Ayling, R., and Newell, D. G. (1996). Increased colonization potential of Campylobacter jejuni strain 81116 after passage through chickens and its implication on the rate of transmission within flocks. Epidemiol. Infect. 117, 213-215. doi: 10.1017/S0950268800001333

Chan, Y. C., and Wiedmann, M. (2008). Physiology and genetics of Listeria monocytogenes survival and growth at cold temperatures. Crit. Rev. Food Sci. Nutr. 49, 237-253. doi: 10.1080/10408390701856272

Chandrashekhar, K., Kassem, I.II, and Rajashekara, G. (2017). Campylobacter jejuni transducer like proteins: chemotaxis and beyond. Gut Microbes 8, 323334. doi: 10.1080/19490976.2017.1279380

Cheng, A. L., Hsu, C. H., Lin, J. K., Hsu, M. M., Ho, Y. F., Shen, T. S., et al. (2001). Phase I clinical trial of curcumin, a chemopreventive agent, in patients with high-risk or pre-malignant lesions. Anticancer Res. 21, e2900.

Chou, T.-C., and Talalay, P. (1984). Quantitative analysis of dose-effect relationships: the combined effects of multiple drugs or enzyme inhibitors. Adv. Enzyme Regul. 22, 27-55. doi: 10.1016/0065-2571(84)90007-4

Chou, T.-C. (2006). Theoretical basis, experimental design, and computerized simulation of synergism and antagonism in drug combination studies. Pharmacol. Rev. 58, 621-681. doi: 10.1124/pr.58.3.10

Chouliara, E., Karatapanis, A., Savvaidis, I. N., and Kontominas, M. G. (2007). Combined effect of oregano essential oil and modified atmosphere packaging on shelf-life extension of fresh chicken breast meat, stored at $4{ }^{\circ} \mathrm{C}$. Food Microbiol. 24, 607-617. doi: 10.1016/j.fm.2006.12.005

Clark, A. G., and Bueschkens, D. H. (1988). Horizontal spread of human and poultry-derived strains of Campylobacter jejuni among broiler chicks held in incubators and shipping boxes. J. Food Protect. 51, 438-441. doi: 10.4315/0362028X-51.6.438

Connerton, P. L., Richards, P. J., Lafontaine, G. M., O’Kane, P. M., Ghaffar, N., Cummings, N. J., et al. (2018). The effect of the timing of exposure to Campylobacter jejuni on the gut microbiome and inflammatory responses of broiler chickens. Microbiome 6, 88. doi: 10.1186/s40168-018-0477-5

Costa, D., and Iraola, G. (2019). Pathogenomics of emerging Campylobacter species. Clin. Microbiol. Rev. 32, e00072-e00018. doi: 10.1128/CMR.00072-18

Cox, N. A., Richardson, L. J., Maurer, J. J., Berrang, M. E., Fedorka-Cray, P. J., Buhr, R. J., et al. (2012). Evidence for horizontal and vertical transmission in Campylobacter passage from hen to her progeny. J. Food Protect. 75, 1896 1902. doi: 10.4315/0362-028.JFP-11-322

Craven, S. E., Stern, N. J., Line, E., Bailey, J. S., Cox, N. A., and Fedorka-Cray, P. (2000). Determination of the incidence of Salmonella spp., Campylobacter jejuni, and Clostridium perfringens in wild birds near broiler chicken houses by sampling intestinal droppings. Avian Diseases 44, 715-720. doi: 10.2307/ 1593118

Crim, S. M., Iwamoto, M., Huang, J. Y., Griffin, P. M., Gilliss, D., Cronquist, A. B., et al. (2014). Incidence and trends of infection with pathogens transmitted commonly through food-Foodborne Diseases Active Surveillance Network, 10 US site-2013. Morbid. Mortal. Weekly Rep. 63, 328. https://www.ncbi.nlm. nih.gov/pmc/articles/PMC5779392/pdf/328-332.pdf.

Crim, S. M., Griffin, P. M., Tauxe, R., Marder, E. P., Gilliss, D., Cronquist, A. B. et al. (2015). Preliminary incidence and trends of infection with pathogens 
transmitted commonly through food-Foodborne Diseases Active Surveillance Network, 10 US site-2014. Morbid. Mortal. Weekly Rep. 64, 495. https:// pubmed.ncbi.nlm.nih.gov/25974634/.

Davidson, P. M., Sofos, J. N., and Branen, A. L. (2005). Antimicrobials in food (Boca Raton, Florida, USA: CRC press).

De, R., Kundu, P., Swarnakar, S., Ramamurthy, T., Chowdhury, A., Nair, G. B., et al. (2009). Antimicrobial activity of curcumin against Helicobacter pylori isolates from India and during infections in mice. Antimicrob. Agents Chemother. 53, 1592-1597. doi: 10.1128/AAC.01242-08

de Kraker, M. E. A., Stewardson, A. J., and Harbarth, S. (2016). Will 10 million people die a year due to antimicrobial resistance by 2050? PloS Med. 13, e1002184. doi: 10.1371/journal.pmed.1002184

Demirok, E., Veluz, G., Stuyvenberg, W. V., Castañeda, M. P., Byrd, A., and Alvarado, C. Z. (2013). Quality and safety of broiler meat in various chilling systems. Poultry Sci. 92, 1117-1126. doi: 10.3382/ps.2012-02493

Di Mario, F., Cavallaro, L. G., Nouvenne, A., Stefani, N., Cavestro, G. M., Iori, V., et al. (2007). A curcumin-based 1-week triple therapy for eradication of Helicobacter pylori infection: something to learn from failure? Helicobacter 12, 238-243. doi: 10.1128/AAC.01242-08

Doulgeraki, A.II, Ercolini, D., Villani, F., and Nychas, G.-J. E. (2012). Spoilage microbiota associated to the storage of raw meat in different conditions. Int. J. Food Microbiol. 157, 130-141. doi: 10.1016/j.ijfoodmicro.2012. 05.020

Doyle, M. P., and Roman, D. J. (1982a). Prevalence and survival of Campylobacter jejuni in unpasteurized milk. Appl. Environ. Microbiol. 44, 1154-1158.

Doyle, M. P., and Roman, D. J. (1982b). Sensitivity of Campylobacter jejuni to drying. J. Food Protect. 45, 507-510. doi: 10.4315/0362-028X-45.6.507

Doyle, M. P. (1984). Association of Campylobacter jejuni with laying hens and eggs. Appl. Environ. Microbiol. 47, 533-536.

El-Shibiny, A., Scott, A., Timms, A., Metawea, Y., Connerton, P., and Connerton, I. (2009). Application of a group II Campylobacter bacteriophage to reduce strains of Campylobacter jejuni and Campylobacter coli colonizing broiler chickens. J. Food Prot. 4, 733-740. doi: 10.4315/0362-028X-72.4.733

Ellis-Iversen, J., Ridley, A., Morris, V., Sowa, A., Harris, J., Atterbury, R., et al. (2012). Persistent environmental reservoirs on farms as risk factors for Campylobacter in commercial poultry. Epidemiol. Infect. 140, 916-924. doi: $10.1017 /$ S095026881100118X

Fernández, A., Soriano, E., López-Carballo, G., Picouet, P., Lloret, E., Gavara, R., et al. (2009). Preservation of aseptic conditions in absorbent pads by using silver nanotechnology. Food Res. Int. 42, 1105-1112. doi: 10.1016/ j.foodres.2009.05.009

Finch, M. J., and Blake, P. A. (1985). Foodborne outbreaks of campylobacteriosis: the United States experienc-1982. Am. J. Epidemiologyl. 122, 262-268. doi: 10.1093/oxfordjournals.aje.a114097

Fischer, S., Kittler, S., Klein, G., and Glünder, G. (2013). Impact of a single phage and a phage cocktail application in broilers on reduction of Campylobacter jejuni and development of resistance. PloS One 8, e78543. doi: 10.1371/ journal.pone. 0078543

Fontanot, M., Iacumin, L., Cecchini, F., Comi, G., and Manzano, M. (2014). Rapid detection and differentiation of important Campylobacter spp. in poultry samples by dot blot and PCR. Food Microbiol. 43, 28-34. doi: 10.1016/ j.fm.2014.05.001

Gaibani, P., Ambretti, S., Viale, P., and Re, M. C. (2019). In-vitro synergistic activity of meropenem/vaborbactam in combination with ceftazidime/ avibactam against KPC-producing Klebsiella pneumoniae. J. Antimicrob. Chemother. 74, 1457-1459. doi: 10.1093/jac/dky557

Gast, R. K., and Beard, C. W. (1990). Production of Salmonella enteritidiscontaminated eggs by experimentally infected hens. Avian Diseases $34,438-$ 446. doi: $10.2307 / 1591433$

Gaynor, E. C., Wells, D. H., MacKichan, J. K., and Falkow, S. (2005). The Campylobacter jejuni stringent response controls specific stress survival and virulence-associated phenotypes. Mol. Microbiol. 56, 8-27. doi: 10.1111/j.13652958.2005.04525.x

Gormley, F. J., Bailey, R. A., Watson, K. A., McAdam, J., Avendaño, S., Stanley, W. A., et al. (2014). Campylobacter colonization and proliferation in the broiler chicken upon natural field challenge is not affected by the bird growth rate or breed. Appl. Environmental Microbiol. 80, 6733-6738. doi: 10.1128/ AEM.02162-14
Grant, C. C., Konkel, M. E., Cieplak, W., and Tompkins, L. S. (1993). Role of flagella in adherence, internalization, and translocation of Campylobacter jejuni in nonpolarized and polarized epithelial cell cultures. Infect. Immunity 61, 1764-1771.

Guard-Petter, J. (2001). The chicken, the egg and Salmonella enteritidis. Environ. Microbiol. 3, 421-430. doi: 10.1046/j.1462-2920.2001.00213.x

Hakeem, M. J., Feng, J., Nilghaz, A., Ma, L., Seah, H. C., Konkel, M. E., et al. (2020). Active Packaging of Immobilized Zinc Oxide Nanoparticles Controls Campylobacter jejuni in Raw Chicken Meat. Appl. Environ. Microbiol. 86, 22. doi: 10.1128/AEM.01195-20

Hald, B., Wedderkopp, A., and Madsen, M. (2000). Thermophilic Campylobacter spp. in Danish broiler production: a cross-sectional survey and a retrospective analysis of risk factors for occurrence in broiler flocks. Avian Pathol. 29, 29. doi: 10.1128/AEM.69.8.4343-4351.2003

Han, C., Wang, L., Yu, K., Chen, L., Hu, L., Chen, K., et al. (2006). Biochemical characterization and inhibitor discovery of shikimate dehydrogenase from Helicobacter pylori. Fed. Eur. Biochem. Societies J. 273, 4682-4692. doi: 10.1111/j.1742-4658.2006.05469.x

Hara-Kudo, Y., and Takatori, K. (2011). Contamination level and ingestion dose of foodborne pathogens associated with infections. Epidemiol. Infect. 139, 15051510. doi: 10.1046/j.1462-2920.2001.00213.x

Hazeleger, W. C., Janse, J. D., Koenraad, P. M., Beumer, R. R., Rombouts, F. M., and Abee, T. (1995). Temperature-dependent membrane fatty acid and cell physiology changes in coccoid forms of Campylobacter jejuni. Appl. Environ. Microbiol. 61, 2713-2719.

Hazeleger, W. C., Wouters, J. A., Rombouts, F. M., and Abee, T. (1998). Physiological activity of Campylobacter jejuni far below the minimal growth temperature. Appl. Environ. Microbiol. 64, 3917-3922.

Hazeleger, W. C., Bolder, N. M., Beumer, R. R., and Jacobs-Reitsma, W. F. (2008). Darkling beetles (Alphitobius diaperinus) and their larvae as potential vectors for the transfer of Campylobacter jejuni and Salmonella enterica serovar paratyphi B variant Java between successive broiler flocks. Appl. Environ. Microbiol. 74, 6887-6891. doi: 10.1128/AEM.00451-08

Hemaiswarya, S., and Doble, M. (2010). Synergistic interaction of phenylpropanoids with antibiotics against bacteria. J. Med. Microbiol. 59, 1469-1476. doi: 10.1099/jmm.0.022426-0

Hendrixson, D. R., and DiRita, V. J. (2004). Identification of Campylobacter jejuni genes involved in commensal colonization of the chick gastrointestinal tract. Mol. Microbiol. 52, 471-484. doi: 10.1111/j.1365-2958.2004.03988.x

Hendrixson, D. R. (2006). A phase-variable mechanism controlling the Campylobacter jejuni FlgR response regulator influences commensalism. Mol. Microbiol. 61, 1646-1659. doi: 10.1111/j.1365-2958.2006.05336.x

Heuer, O. E., Pedersen, K., Andersen, J. S., and Madsen, M. (2001). Prevalence and antimicrobial susceptibility of thermophilic Campylobacter in organic and conventional broiler flocks. Lett. Appl. Microbiol. 33, 269-274. doi: 10.1046/ j.1472-765X.2001.00994.x

Hiett, K. L., Stern, N. J., Fedorka-Cray, P., Cox, N. A., Musgrove, M. T., and Ladely, S. (2002). Molecular subtype analyses of Campylobacter spp. from Arkansas and California poultry operations. Appl. Environ. Microbiol. 68, 6220-6236. doi: 10.1128/AEM.68.12.6220-6236.2002

Hudson, J. A., Nicol, C., Wright, J., Whyte, R., and Hasell, S. K. (1999). Seasonal variation of Campylobacter types from human cases, veterinary cases, raw chicken, milk and water. J. Appl. Microbiol. 87, 115-124. doi: 10.1046/j.13652672.1999.00806.x

Hue, O., Allain, V., Laisney, M.-J., Le Bouquin, S., Lalande, F., Petetin, I., et al. (2011). Campylobacter contamination of broiler caeca and carcasses at the slaughterhouse and correlation with Salmonella contamination. Food Microbiol. 28, 862-868. doi: 10.1016/j.fm.2010.11.003

Hughes, R.-A., Hallett, K., Cogan, T., Enser, M., and Humphrey, T. (2009). The response of Campylobacter jejuni to low temperature differs from that of Escherichia coli. Appl. Environ. Microbiol. 75, 6292-6298. doi: 10.1128/ AEM.00993-09

Humphery, T. J., Henley, A., and Lanning, D. G. (1993). The colonization of broiler chickens with Campylobacter jejuni: some epidemiological investigations. Epidemiol. Infect. 110, 601-607. doi: 10.1017/ s0950268800051025

Humphrey, S., Chaloner, G., Kemmett, K., Davidson, N., Williams, N., Kipar, A., et al. (2014). Campylobacter jejuni is not merely a commensal in commercial 
broiler chickens and affects bird welfare. MBio 5, e01364-e01314. doi: 10.1128/ mBio.01364-14

Hwang, S., Kim, M., Ryu, S., and Jeon, B. (2011). Regulation of oxidative stress response by CosR, an essential response regulator in Campylobacter jejuni. PloS One 6, e22300. doi: 10.1371/journal.pone.0022300

Hyldgaard, M., Mygind, T., and Meyer, R. L. (2012). Essential oils in food preservation: mode of action, synergies, and interactions with food matrix components. Front. Microbiol. 3:3389/fmicb.2012.00012:12. doi: 10.3389/ fmicb.2012.00012

Ijaz, U. Z., Sivaloganathan, L., McKenna, A., Richmond, A., Kelly, C., Linton, M., et al. (2018). Comprehensive longitudinal microbiome analysis of the chicken cecum reveals a shift from competitive to environmental drivers and a window of opportunity for Campylobacter. Front. Microbiol. 9:3389/fmicb.2018.02452: 2452. doi: $10.3389 /$ fmicb.2018.02452

Jackson, W. C. (1999). Survey shows that poultry processors can save money by conserving water (North Carolina: Cooperative Extension Service). Available at: https://fbns.ncsu.edu//extension_program/documents/poultry_conserve_ water.pdf.

Jacobs-Reitsma, W. F., Van de Giessen, A. W., Bolder, N. M., and Mulder, R. (1995). Epidemiology of Campylobacter spp. at two Dutch broiler farms. Epidemiol. Infect. 114, 413-421. doi: 10.1017/S0950268800052122

Jacobs-Reitsma, W. F. (1995). Campylobacter bacteria in breeder flocks. Avian Diseases 39 (2), 355-359.

Jagannathan, A., Constantinidou, C., and Penn, C. W. (2001). Roles of rpoN, fliA, and flgR in Expression of Flagella in Campylobacter jejuni. J. Bacteriol. 183, 2937-2942. doi: 10.1128/JB.183.9.2937-2942.2001

Jamroz, D., Wertelecki, T., Houszka, M., and Kamel, C. (2006). Influence of diet type on the inclusion of plant origin active substances on morphological and histochemical characteristics of the stomach and jejunum walls in chicken. J. Anim. Physiol. Anim. Nutr. 90, 255-268. doi: 10.1111/j.1439-0396. 2005.00603.x

Jia, J., Zhu, F., Ma, X., Cao, Z. W., Li, Y. X., and Chen, Y. Z. (2009). Mechanisms of drug combinations: interaction and network perspectives. Nat. Rev. Drug Discov. 8, 111. doi: 10.1038/nrd2683

Jorgensen, F., Bailey, R., Williams, S., Henderson, P., Wareing, D. R., Bolton, F. J., et al. (2002). Prevalence and numbers of Salmonella and Campylobacter spp. on raw, whole chickens in relation to sampling methods. Int. J. Food Microbiol. 76, 151-164. doi: 10.1016/S0168-1605(02)00027-2

Kaakoush, N. O., Sodhi, N., Chenu, J. W., Cox, J. M., Riordan, S. M., and Mitchell, H. M. (2014). The interplay between Campylobacter and Helicobacter species and other gastrointestinal microbiota of commercial broiler chickens. Gut Pathogens 6:18. doi: 10.1186/1757-4749-6-18

Kaakoush, N. O., Castaño-Rodríguez, N., Mitchell, H. M., and Man, S. M. (2015). Global epidemiology of Campylobacter infection. Clin. Microbiol. Rev. 28, 687720. doi: 10.1128/CMR.00006-15

Kärenlampi, R., and Hänninen, M.-L. (2004). Survival of Campylobacter jejuni on various fresh produce. Int. J. Food Microbiol. 97, 187-195. doi: 10.1016/ j.ijfoodmicro.2004.04.019

Karlyshev, A. V., and Wren, B. W. (2001). Detection and Initial characterization of novel capsular polysaccharide among diverse Campylobacter jejuni strains using alcian blue dye. J. Clin. Microbiol. 39, 279-284. doi: 10.1128/ JCM.39.1.279-284.2001

Kaur, S., Modi, N. H., Panda, D., and Roy, N. (2010). Probing the binding site of curcumin in Escherichia coli and Bacillus subtilis FtsZ-a structural insight to unveil antibacterial activity of curcumin. Eur. J. Medicinal Chem. 45, 42094214. doi: 10.1016/j.ejmech.2010.06.015

Keener, K. M., Bashor, M. P., Curtis, P. A., Sheldon, B. W., and Kathariou, S. (2004). Comprehensive review of Campylobacter and poultry processing. Compr. Rev. Food Sci. Food Safety 3, 105-116. doi: 10.1111/j.15414337.2004.tb00060.x

Kelly, A. F., Park, S. F., Bovill, R., and Mackey, B. M. (2001). Survival of Campylobacter jejuni during stationary phase: evidence for the absence of a phenotypic stationary-phase response. Appl. Environ. Microbiol. 67, 22482254. doi: 10.1128/AEM.67.5.2248-2254.2001

Kiess, A. S., Kenney, P. B., and Nayak, R. R. (2007). Campylobacter detection in commercial turkeys. Poultry Sci. 48, 567-572. doi: 10.1080/00071660701573094

Kim, S. A., Park, S. H., Lee, S.II, Owens, C. M., and Ricke, S. C. (2017). Assessment of chicken carcass microbiome responses during processing in the presence of commercial antimicrobials using a next generation sequencing approach. Sci. Rep. 7:43354. doi: 10.1038/srep43354

Kittler, S., Fischer, S., Abdulmawjood, A., Glünder, G., and Klein, G. (2013). Effect of bacteriophage application on Campylobacter jejuni loads in commercial broiler flocks. Appl. Environ. Microbiol. 79, 7525-7533. doi: 10.1128/ AEM.02703-13

Konkel, M. E., Garvis, S. G., Tipton, S. L., Anderson Donald E, J., and Cieplak Witold, J. (1997). Identification and molecular cloning of a gene encoding a fibronectin-binding protein (CadF) from Campylobacter jejuni. Mol. Microbiol. 24, 953-963. doi: 10.3390/microorganisms8030389

Konkel, M. E., Kim, B. J., Klena, J. D., Young, C. R., and Ziprin, R. (1998). Characterization of the thermal stress response of Campylobacter jejuni. Infect. Immunity 66, 3666-3672. doi: 10.1128/IAI.66.8.3666-3672.1998

Konkel, M. E., Gray, S. A., Kim, B. J., Garvis, S. G., and Yoon, J. (1999a). Identification of the enteropathogens Campylobacter jejuni and Campylobacter coli based on the cadF virulence gene and its product. J. Clin. Microbiol. 37, 510-517. doi: 10.1128/JCM.37.3.510-517.1999

Konkel, M. E., Kim, B. J., Rivera-Amill, V., and Garvis, S. G. (1999b). Bacterial secreted proteins are required for the internalization of Campylobacter jejuni into cultured mammalian cells. Mol. Microbiol. 32, 691-701. doi: 10.1046/ j.1365-2958.1999.01376.x

Kotula, K. L., and Pandya, Y. (1995). Bacterial profile of broiler chickens upon entering the processing plant. J. Food Protect. 58, 1326-1329. doi: 10.4315/ 0362-028X-58.12.1326

Kubota, K., Kasuga, F., Iwasaki, E., Inagaki, S., Sakurai, Y., Komatsu, M., et al. (2011). Estimating the burden of acute gastroenteritis and foodborne illness caused by Campylobacter, Salmonella, and Vibrio parahaemolyticus by using populationbased telephone survey data, Miyagi Prefecture, Japato 2006. J. Food Protect. 74, 1592-1598. doi: 10.4315/0362-028X.JFP-10-387

Labrie, S. J., Samson, J. E., and Moineau, S. (2010). Bacteriophage resistance mechanisms. Nat. Rev. Microbiol. 8, 317. doi: 10.1038/nrmicro2315

Lanier, W. A., Hale, K. R., Geissler, A. L., and Dewey-Mattia, D. (2018). Chicken liver-associated outbreaks of campylobacteriosis and salmonellosis, United State-2016: identifying opportunities for prevention. Foodborne Pathog. Disease 15, 726-733. doi: 10.1089/fpd.2018.2489

Lao, C. D., Ruffin, M. T., Normolle, D., Heath, D. D., Murray, S.II, Bailey, J. M., et al. (2006). Dose escalation of a curcuminoid formulation. BMC Complement. Altern. Medicine 6:10. doi: 10.1186/1472-6882-6-10

Lara-Tejero, M., and Galán, J. E. (2001). CdtA, CdtB, and CdtC form a tripartite complex that is required for cytolethal distending toxin activity. Infect. Immunity 69, 4358-4365. doi: 10.1128/IAI.69.7.4358-4365.2001

Li, M., Havelaar, A. H., Hoffmann, S., Hald, T., Kirk, M. D., Torgerson, P. R., et al. (2019). Global disease burden of pathogens in animal source food. PloS One 14 e0216545. doi: 10.1371/journal.pone.0216545

Lone, A., Anany, H., Hakeem, M., Aguis, L., Avdjian, A.-C., Bouget, M., et al. (2016). Development of prototypes of bioactive packaging materials based on immobilized bacteriophages for control of growth of bacterial pathogens in foods. Int. J. Food Microbiol. 217, 49-58. doi: 10.1016/j.ijfoodmicro.2015. 10.011

Mace, S., Haddad, N., Zagorec, M., and Tresse, O. (2015). Influence of measurement and control of microaerobic gaseous atmospheres in methods for Campylobacter growth studies. Food Microbiol. 52, 169-176. doi: 10.1016/ j.fm.2015.07.014

Man, S. M. (2011). The clinical importance of emerging Campylobacter species. Nat. Rev. Gastroenterol. Hepatol. 8, 669. doi: 10.1038/nrgastro.2011.191

Mavri, A., and Smole Možina, S. (2013). Development of antimicrobial resistance in Campylobacter jejuni and Campylobacter coli adapted to biocides. Int. J. Food Microbiol. 160, 304-312. doi: 10.1016/j.ijfoodmicro. 2012.11.006

McFadyean, S. J., and Stockman, S. S. (1913). Report of the Departmental Committee Appointed by the Board of Agriculture and Fisheries to Inquire Into Epizootic Abortion. Appendix to Part III, Abortion in Sheep. HM Stationery Office.

McMillin, K. W. (2008). Where is MAP going? A review and future potential of modified atmosphere packaging for meat. Meat Sci. 80, 43-65. doi: 10.1016/ j.meatsci.2008.05.028

Miyamoto, T., Baba, E., Tanaka, T., Sasai, K., Fukata, T., and Arakawa, A. (1997). Salmonella enteritidis contamination of eggs from hens inoculated by vaginal, 
cloacal, and intravenous routes. Avian Diseases 42, 296-303. doi: 10.2307/ 1592181

Mughini-Gras, L., Smid, J. H., Wagenaar, J. A., De Boer, A., Havelaar, A. H., Friesema, I. H. M., et al. (2014). Campylobacteriosis in returning travellers and potential secondary transmission of exotic strains. Epidemiol. Infect. 142, 1277-1288. doi: 10.1017/S0950268813002069

Murphy, C., Carroll, C., and Jordan, K. N. (2006). Environmental survival mechanisms of the foodborne pathogen Campylobacter jejuni. J. Appl. Microbiol. 100, 623-632. doi: 10.1111/j.1365-2672.2006.02903.x

Neal-McKinney, J. M., Samuelson, D. R., Eucker, T. P., Nissen, M. S., Crespo, R., and Konkel, M. E. (2014). Reducing Campylobacter jejuni colonization of poultry via vaccination. PloS One 9, e114254. doi: 10.1371/journal.pone. 0114254

Newell, D. G., and Fearnley, C. (2003). Sources of Campylobacter colonization in broiler chickens. Appl. Environ. Microbiol. 69, 4343-4351. doi: 10.1128/ AEM.69.8.4343-4351.2003

Newell, D. G., Elvers, K. T., Dopfer, D., Hansson, I., Jones, P., James, S., et al. (2011). Biosecurity-based interventions and strategies to reduce Campylobacter spp. on poultry farms. Appl. Environ. Microbiol. 77, 8605-8614. doi: 10.1128/ AEM.01090-10

Nielsen, H. L., Ejlertsen, T., Engberg, J., and Nielsen, H. (2013). High incidence of Campylobacter concisus in gastroenteritis in North Jutland, Denmark: a population-based study. Clin. Microbiol. Infect. 19, 445-450. doi: 10.1111/ j.1469-0691.2012.03852.x

Northcutt, J. K., Berrang, M. E., Dickens, J. A., Fletcher, D. L., and Cox, N. A. (2003). Effect of broiler age, feed withdrawal, and transportation on levels of coliforms, Campylobacter, Escherichia coli and Salmonella on carcasses before and after immersion chilling. Poultry Sci. 82, 169-173. doi: 10.1093/ps/82.1.169

Odds, F. C. (2003). Synergy, antagonism, and what the chequerboard puts between them. J. Antimicrob. Chemother. 52:1. doi: 10.1093/ps/82.1.169

Oh, E., and Jeon, B. (2015). Synergistic anti-Campylobacter jejuni activity of fluoroquinolone and macrolide antibiotics with phenolic compounds. Front. Microbiol. 6:3389/fmicb.2015.01129:1129. doi: 10.3389/fmicb.2015.01129

Oh, E., McMullen, L., and Jeon, B. (2015). High prevalence of hyper-aerotolerant Campylobacter jejuni in retail poultry with potential implication in human infection. Front. Microbiol. 6:3389/fmicb.2015.01263:1263. doi: 10.3389/ fmicb.2015.01263

Panea, B., Ripoll, G., González, J., Fernández-Cuello, Á., and Albertí, P. (2014). Effect of nanocomposite packaging containing different proportions of $\mathrm{ZnO}$ and Ag on chicken breast meat quality. J. Food Engineering 123, 104-112. doi: 10.1016/j.jfoodeng.2013.09.029

Park, S. (1996). Microorganisms in foods 5: Characteristics of microbial pathogens (London, UK: Springer Science \& Business Media).

Parkhill, J., Wren, B. W., Mungall, K., Ketley, J. M., Churcher, C., Basham, D., et al. (2000). The genome sequence of the food-borne pathogen Campylobacter jejuni reveals hypervariable sequences. Nature 403, 665. doi: 10.1038/35001088

Pearson, A. D., Greenwood, M., Healing, T. D., Rollins, D., Shahamat, M., Donaldson, J., et al. (1993). Colonization of broiler chickens by waterborne Campylobacter jejuni. Appl. Environ. Microbiol. 59, 987-996.

Petersen, L., Nielsen, E. M., and On, S. L. W. (2001). Serotype and genotype diversity and hatchery transmission of Campylobacter jejuni in commercial poultry flocks. Vet. Microbiol. 82, 141-154. doi: 10.1016/s0378-1135(01)00382-0

Pothakos, V., Taminiau, B., Huys, G., Nezer, C., Daube, G., and Devlieghere, F. (2014). Psychrotrophic lactic acid bacteria associated with production batch recalls and sporadic cases of early spoilage in Belgium between 2010 and 2014. Int. J. Food Microbiol. 191, 157-163. doi: 10.1016/j.ijfoodmicro.2014.09.013

Powell, L. F., Lawes, J. R., Clifton-Hadley, F. A., Rodgers, J., Harris, K., Evans, S. J., et al. (2012). The prevalence of Campylobacter spp. in broiler flocks and on broiler carcases, and the risks associated with highly contaminated carcases. Epidemiol. Infect. 140, 2233-2246. doi: 10.1017/S0950268812000040

Ravel, A., Nesbitt, A., Marshall, B., Sittler, N., and Pollari, F. (2010). Description and burden of travel-related cases caused by enteropathogens reported in a Canadian community. J. Travel Med. N. 18, 8-19. doi: 10.1111/j.17088305.2010.00471.x

Ravindran, P. N., Nirmal-Babu, K., and Shylaja, M. (2003). Cinnamon and cassia: the genus Cinnamomum. CRC Press. doi: 10.1201/9780203590874

Ringoir, D. D., and Korolik, V. (2003). Colonisation phenotype and colonisation potential differences in Campylobacter jejuni strains in chickens before and after passage in-vivo. Vet. Microbiol. 92, 225-235. doi: 10.1016/S0378-1135(02) 00378-4

Ritchie, H., and Roser, M. (2017). Meat and Dairy Production. Our World Data.

Rivera-Amill, V., Kim, B. J., Seshu, J., and Konkel, M. E. (2001). Secretion of the virulence-associated Campylobacter invasion antigens from Campylobacter jejuni requires a stimulatory signal. J. Infect. Diseases 183, 1607-1616. doi: $10.1086 / 320704$

Rouger, A., Tresse, O., and Zagorec, M. (2017). Bacterial contaminants of poultry meat: sources, species, and dynamics. Microorganisms 5, 50. doi: 10.3390/ microorganisms 5030050

Rudrappa, T., and Bais, H. P. (2008). Curcumin, a known phenolic from Curcuma longa, attenuates the virulence of Pseudomonas aeruginosa PAO1 in whole plant and animal pathogenicity models. J. Agric. Food Chem. 56, 1955-1962. doi: $10.1021 /$ jf072591j

Rusin, P. A., Rose, J. B., Haas, C. N., and Gerba, C. P. (1997). "Risk assessment of opportunistic bacterial pathogens in drinking water," in Reviews of environmental contamination and toxicology (New York, NY: Springer), 5783. doi: 10.1007/978-1-4612-1964-4_2

Sahin, O., Morishita, T. Y., and Zhang, Q. (2002). Campylobacter colonization in poultry: sources of infection and modes of transmission. Anim. Health Res. Rev. 3, 95-105. doi: 10.1079/AHRR200244

Santini, C., Baffoni, L., Gaggia, F., Granata, M., Gasbarri, R., Di Gioia, D., et al. (2010). Characterization of probiotic strains: an application as feed additives in poultry against Campylobacter jejuni. Int. J. Food Microbiol. 141, S98-S108. doi: 10.1016/j.ijfoodmicro.2010.03.039

Sarkar, A., De, R., and Mukhopadhyay, A. K. (2016). Curcumin as a potential therapeutic candidate for Helicobacter pylori associated diseases. World J. Gastroenterol. 22:2736. doi: 10.3748/wjg.v22.i9.2736

Saxena, M., John, B., Mu, M., Van, T. T. H., Taki, A., Coloe, P. J., et al. (2013). Strategies to reduce Campylobacter colonisation in chickens. Proc. Vaccinol. 7, 40-43. doi: 10.1016/j.provac.2013.06.008

Sears, A., Baker, M. G., Wilson, N., Marshall, J., Muellner, P., Campbell, D. M., et al. (2011). Marked campylobacteriosis decline after interventions aimed at poultry, New Zealand. Emerg. Infect. Diseases 17, 1007. doi: 10.3201/ eid1706.101272

Service, F. safety and inspection (2018). Safe and suitable ingredients used in the production of meat, poultry, and egg products. Food Safety and Inspection Service (FSIS). Available at: https://www.fsis.usda.gov/wps/wcm/connect/ bab10e09-aefa-483b-8be8-809a1f051d4c/7120.1.pdf?MOD=AJPERES.

Shanker, S., Lee, A., and Sorrell, T. C. (1986). Campylobacter jejuni in broilers: the role of vertical transmission. Epidemiol. Infect. 96, 153-159. doi: 10.1017/ S002217240006592X

Shanker, S., Lee, A., and Sorrell, T. C. (1990). Horizontal transmission of Campylobacter jejuni amongst broiler chicks: experimental studies. Epidemiol. Infect. 104, 101-110.

Sirelkhatim, A., Mahmud, S., Seeni, A., Kaus, N. H. M., Ann, L. C., Bakhori, S. K. M., et al. (2015). Review on zinc oxide nanoparticles: antibacterial activity and toxicity mechanism. Nano Microbiol. Lett. 7, 219-242. doi: 10.1017/s0950268800054571

Skirrow, M. B. (1977). Campylobacter enteritis: a" new" disease. Br. Med. J. 2, 9-11. doi: $10.1136 / \mathrm{bmj} \cdot 2.6078 .9$

Skirrow, M. B. (2006). John McFadyean and the centenary of the first isolation of Campylobacter species. Clin. Infect. Diseases 43, 1213-1217. doi: 10.1086/508201

Slader, J., Domingue, G., Jørgensen, F., McAlpine, K., Owen, R. J., Bolton, F. J., et al. (2002). Impact of transport crate reuse and of catching and processing on Campylobacter and Salmonella contamination of broiler chickens. Appl. Environmntal Microbiol. 68, 713-719. doi: 10.1128/AEM.68.2.713-719.2002

Smith, K., Reimers, N., Barnes, H. J., Lee, B. C., Siletzky, R., and Kathariou, S. (2004). Campylobacter colonization of sibling turkey flocks reared under different management conditions. J. Food Protect. 67, 1463-1468. doi: 10.4315/0362-028X-67.7.1463

Snelling, W. J., McKenna, J. P., Hack, C. J., Moore, J. E., and Dooley, J. S. G. (2006). An examination of the diversity of a novel Campylobacter reservoir. Arch. Microbiol. 186, 31-40. doi: 10.1007/s00203-006-0119-3

Stern, N. J., and Kotula, A. W. (1982). Survival of Campylobacter jejuni inoculated into ground beef. Appl. Environmtal Microbiol. 44, 1150-1153.

Stern, N. J., and Robach, M. C. (2003). Enumeration of Campylobacter spp. in broiler feces and in corresponding processed carcasses. J. Food Protect. 66, 1557-1563. doi: 10.4315/0362-028X-66.9.1557 
Stern, N. J., Fedorka-Cray, P., Bailey, J. S., Cox, N. A., Craven, S. E., Hiett, K. L., et al. (2001). Distribution of Campylobacter spp. in selected US poultry production and processing operations. J. Food Protect. 64, 1705-1710. doi: 10.4315/0362-028X-64.11.1705

Svetoch, E. A., and Stern, N. J. (2010). Bacteriocins to control Campylobacter spp. in poultry-a review. Poultry Sci. 89, 1763-1768. doi: 10.3382/ps.2010-00659

Tajkarimi, M. M., Ibrahim, S. A., and Cliver, D. O. (2010). Antimicrobial herb and spice compounds in food. Food Control 21, 1199-1218. doi: 10.1016/ j.foodcont.2010.02.003

Thies, F. L., Weishaupt, A., Karch, H., Hartung, H.-P., and Giegerich, G. (1999). Cloning, sequencing and molecular analysis of the Campylobacter jejuni groESL bicistronic operon. Microbiology 145, 89-98. doi: 10.1099/13500872-145-1-89

Thomas, C. J., and McMeekin, T. A. (1980). Contamination of broiler carcass skin during commercial processing procedures: an electron microscopic study. Appl. Environ. Microbiol. 40, 133-144.

Thomas, M. K., Murray, R., Flockhart, L., Pintar, K., Pollari, F., Fazil, A., et al. (2013). Estimates of the burden of foodborne illness in Canada for 30 specified pathogens and unspecified agents, circa 2006. Foodborne Pathog. Disease 10, 639-648. doi: 10.1089/fpd.2012.1389

Tresse, O., Alvarez-Ordóñez, A., and Connerton, I. F. (2017). Editorial: About the Foodborne Pathogen Campylobacter. Front. Microbiol. 8, 1908. doi: 10.3389/ fmicb.2017.01908

Turonova, H., Haddad, N., Hernould, M., Chevret, D., Pazlarova, J., and Tresse, O. (2017). Profiling of Campylobacter jejuni proteome in exponential and stationary phase of growth. Front. Microbiol. 8:3389/fmicb.2017.00913:913. doi: $10.3389 /$ fmicb.2017.00913

Tyagi, P., Singh, M., Kumari, H., Kumari, A., and Mukhopadhyay, K. (2015). Bactericidal activity of curcumin $\mathrm{I}$ is associated with damaging of bacterial membrane. PloS One 10, e0121313. doi: 10.1371/journal.pone.0121313

Ushanov, L., Lasareishvili, B., Janashia, I., and Zautner, A. E. (2020). Application of Campylobacter jejuni phages: challenges and perspectives. Animals 2, 279. doi: 10.3390/ani10020279

Uyttendaele, M., Schukkink, R., Van Gemen, B., and Debevere, J. (1996). Comparison of the nucleic acid amplification system NASBA ${ }^{\circledR}$ and agar isolation for detection of pathogenic Campylobacters in naturally contaminated poultry. J. Food Protect. 59, 683-687. doi: 10.4315/0362-028X-59.7.683

Van de Braak, S., and Leijten, G. (1999). Essential oils and oleoresins: a survey in the Netherlands and other major markets in the European Union. Centre Promotion Imports Develop. Countries. 116.

Van de Giessen, A., Mazurier, S.II, Jacobs-Reitsma, W., Jansen, W., Berkers, P., Ritmeester, W., et al. (1992). Study on the epidemiology and control of Campylobacter jejuni in poultry broiler flocks. Appl. Environ. Microbiol. 58, 1913-1917.

Van der Stel, A.-X. M., van Mourik, A., Lanniewski, P., van der Putten, J. P. M., Jagusztyn-Krynicka, E. K., and Wosten, M. M. S. M. (2015). The Campylobacter jejuni RacRS two-component system activates the glutamate synthesis by directly upregulating $\gamma$-glutamyltranspeptidase (GGT). Front. Microbiol. 6:3389/fmicb.2015.00567:567. doi: 10.3389/fmicb.2015.00567

Vegge, C. S., Jansen van Rensburg, M. J., Rasmussen, J. J., Maiden, M. C. J., Johnsen, L. G., Danielsen, M., et al. (20161877). Glucose metabolism via the Entner-Doudoroff pathway in Campylobacter: a rare trait that enhances survival and promotes biofilm formation in some isolates. Front. Microbiol. 7, 1877. doi: 10.3389/fmicb.2016.01877

Velayudhan, J., Jones, M. A., Barrow, P. A., and Kelly, D. J. (2004). L-serine catabolism via an oxygen-labile L-serine dehydratase is essential for colonization of the avian gut by Campylobacter jejuni. Infect. Immunity 72 , 260-268. doi: 10.1128/IAI.72.1.260-268.2004

Véron, M., and Chatelain, R. (1973). Taxonomic study of the genus Campylobacter Sebald and Véron and designation of the neotype strain for the type species, Campylobacter fetus (Smith and Taylor) Sebald and Véron. Int. J. System. Evol. Microbiol. 23, 122-134. doi: 10.1099/00207713-23-2-122

Vetvicka, V., Vetvickova, J., and Fernandez-Botran, R. (2016). Effects of curcumin on Helicobacter pylori infection. Ann. Trans. Medicine's 4, 479-485. doi: $10.21037 / \mathrm{atm} .2016 .12 .52$
Vidal, A. B., Colles, F. M., Rodgers, J. D., McCarthy, N. D., Davies, R. H., Maiden, M. C. J., et al. (2016). Genetic diversity of Campylobacter jejuni and Campylobacter coli isolates from conventional broiler flocks and the impacts of sampling strategy and laboratory method. Appl. Environ. Microbiol. 82, 2347-2355. doi: 10.1128/AEM.03693-15

Wagenaar, J. A., Van Bergen, M. A., Mueller, M. A., Wassenaar, T. M., and Carlton, R. M. (2005). Phage therapy reduces Campylobacter jejuni colonization in broilers. Vet. Microbiol. 3-4, 275-283. doi: 10.1016/ j.vetmic.2005.06.002

Walker, L. J., Wallace, R. L., Smith, J. J., Graham, T., Saputra, T., Symes, S., et al. (2019). Prevalence of Campylobacter coli and Campylobacter jejuni in Retail Chicken, Beef, Lamb, and Pork Products in Three Australian States. J. Food Protect. 82, 2126-2134. doi: 10.4315/0362-028X.JFP-19-146

Wallace, J. S., Stanley, K. N., Currie, J. E., Diggle, P. J., and Jones, K. (1997). Seasonality of thermophilic Campylobacter populations in chickens. J. Appl. Microbiol. 82, 219-224. doi: 10.1111/j.1365-2672.1997.tb03576.x

Wedderkopp, A., Gradel, K. O., Jørgensen, J. C., and Madsen, M. (2001). Preharvest surveillance of Campylobacter and Salmonella in Danish broiler flocks: a 2-year study. Int. J. Food Microbiol. 68, 53-59. doi: 10.1016/S0168-1605(01) 00463-9

Whyte, P., Collins, J. D., McGill, K., Monahan, C., and O'mahony, H. (2001). The effect of transportation stress on excretion rates of campylobacters in marketage broilers. Poultry Sci. 80, 817-820.

Wilkinson, J. M. (2011). Re-defining efficiency of feed use by livestock. Animal 5, 1014-1022. doi: 10.1093/ps/80.6.817

Willis, W. L., and Murray, C. (1997). Campylobacter jejuni seasonal recovery observations of retail market broilers. Poultry Sci. 76, 314-317. doi: 10.1093/ps/ 76.2 .314

Xie, Y., He, Y., Irwin, P. L., Jin, T., and Shi, X. (2011). Antibacterial activity and mechanism of action of zinc oxide nanoparticles against Campylobacter jejuni. Appl. Environ. Microbiol. 77, 2325-2331. doi: 10.1128/AEM.02149-10

Yang, H., Li, Y., and Johnson, M. G. (2001). Survival and death of Salmonella Typhimurium and Campylobacter jejuni in processing water and on chicken skin during poultry scalding and chilling. J. Food Protect. 64, 770-776. doi: 10.4315/0362-028X-64.6.770

Yao, R., Burr, D. H., and Guerry, P. (1997). CheY-mediated modulation of Campylobacter jejuni virulence. Mol. Microbiol. 23, 1021-1031. doi: 10.1046/ j.1365-2958.1997.2861650.x

Young, K. T., Davis, L. M., and DiRita, V. J. (2007). Campylobacter jejuni: molecular biology and pathogenesis. Nat. Rev. Microbiol. 5, 665-679. doi: $10.1038 /$ nrmicrol718

Zaidi, S. F. H., Yamada, K., Kadowaki, M., Usmanghani, K., and Sugiyama, T. (2009). Bactericidal activity of medicinal plants, employed for the treatment of gastrointestinal ailments, against Helicobacter pylori. J. Ethnopharmacologyl 121, 286-291. doi: 10.1016/j.jep.2008.11.001

Zhang, Q. Q., Han, Y. Q., Cao, J. X., Xu, X. L., Zhou, G. H., and Zhang, W. Y. (2012). The spoilage of air-packaged broiler meat during storage at normal and fluctuating storage temperatures. Poultry Sci. 91, 208-214. doi: 10.3382/ ps.2011-01519

Zhou, X., Seto, S. W., Chang, D., Kiat, H., Razmovski-Naumovski, V., Chan, K., et al. (2016). Synergistic effects of Chinese herbal medicine: a comprehensive review of methodology and current research. Front. Pharmacol. 7:3389/ fphar.2016.00201:201. doi: 10.3389/fphar.2016.00201

Conflict of Interest: The authors declare that the research was conducted in the absence of any commercial or financial relationships that could be construed as a potential conflict of interest.

Copyright $(0) 2021$ Hakeem and Lu. This is an open-access article distributed under the terms of the Creative Commons Attribution License (CC BY). The use, distribution or reproduction in other forums is permitted, provided the original author(s) and the copyright owner(s) are credited and that the original publication in this journal is cited, in accordance with accepted academic practice. No use, distribution or reproduction is permitted which does not comply with these terms. 